\title{
Seepocken der deutschen Küstengewässer
}

\author{
Gertraud Luther \\ Biologische Anstalt Helgoland (Litoralstation); D-2282 List/Sylt, \\ Bundesrepublik Deutschland
}

\begin{abstract}
Barnacles of German coastal waters. An attempt is made to provide a guide for the identification of seven barnacle species occurring in German coastal waters of the western Baltic and the North Sea. Variations in morphological characters observed in sessile adults are described, and figures drawn to differentiate the larvae of the nauplius and cypris stage. The information available on the distribution and ecology of the barnacles considered is reviewed.
\end{abstract}

\section{EINLEITUNG}

Die Seepocken gehören trotz ihrer Kleinheit zu den auffälligsten sessilen Bewohnern der Gezeitengürtel. Mit dicht gepackten Kolonien überziehen sie jedes feste Substrat: das anstehende Gestein ebenso wie Küstenschutz- und Hafenanlagen. Auch auf lebenden und abgestorbenen Organismen (Krebsen, Mollusken und deren Schalen) sind sie zu finden, auf treibendem Material (Holz, Glas- und Metallkörpern, Kunststoffteilen und Algen), auf Bojen und Schiffsrümpfen. Die hohe Fortpflanzungsrate begünstigt bei selbst ungewöhnlich schwierigen Umweltbedingungen die Verbreitung der Arten.

Erst um die Mitte des vorigen Jahrhunderts gelang es, die Zugehörigkeit der Seepocken zum Stamm Crustacea nachzuweisen. Thompson (1830) entdeckte erstmals im Jahre 1826 die für die Krebse typische Larvenform, den Nauplius, als freischwimmendes Jugendstadium bei den Seepocken und beobachtete über ein weiteres Stadium, der Cypris, die Metamorphose zur festsitzenden adulten Form. Darwin war von der Eigenart dieser Tiergruppe derart beeindruckt, daß er ihr einen Großteil seiner Forschungsarbeit widmete. Seine Schriften von 1851 und 1854 "A monograph on the subclass Cirripedia" zählen heute noch zu den grundlegenden Werken über die Rankenfüßer. Zur Bestimmung benutzte er fast ausschließlich die Platten des Kalkgehäuses als taxonomisches Kennzeichen.

Von den mehr als 150 Arten der Seepocken sind nur wenige Formen im Bereich der deutschen Küstengewässer zu finden. Ihre Identifizierung ist durch die Veränderlichkeit des Kalkgehäuses in Abhängigkeit der Standortbedingungen erschwert. Darum wird mit der vorliegenden Arbeit ein ausführlicher Bestimmungsschlüssel mit zahlreichen Abbildungen vorgelegt. Detaillierte Angaben sollen auch ein Bestimmen der Seepokkenlarven ermöglichen. Zur Einführung wird die allgemeine Gestalt einschließlich der Metamorphose erläutert. Im Anschluß an den Bestimmungsschlüssel folgt eine Litera- 
turübersicht zur Okologie der Seepocken an den deutschen Meeresküsten. In einem Anhang werden die pelagischen Entenmuscheln beschrieben.

\section{MORPHOLOGIE}

Die Seepocken sind sekundär zur sessilen Lebensweise übergegangen und haben, wie bei festsitzenden Organismen häufig zu beobachten, einen annähernd radiärsymmetrischen Grundriß. Sie besitzen als Rankenfüße oder Cirren bezeichnete Rumpfextremitäten, die einer fischenden oder filtrierenden Ernährungsweise dienen. Aus dieser Umbildung ergab sich der Name der Unterklasse "Cirripedia, Rankenfüßer". Die Befruchtung erfolgt bei den Crustaceen über eine innere Begattung. Abweichend von den meist getrenntgeschlechtigen Krebsformen führen die Seepocken als Zwitter eine gegenseitige Kopulation durch, womit der Nachteil der Sessilität ausgeglichen wird. Die besamten Eizellen verbleiben im Schutz der Mantelhöhle, bis sie als frei bewegliche Larven, dem ersten Naupliusstadium, ins Meerwasser entlassen werden.

\section{Bau der Larve}

Die Nauplien der Rankenfüßer unterscheiden sich.von anderen Krebslarven durch die mehr oder weniger dreieckige Umrißlinie des Rückenschildes mit seinen beiden seitlich ausgezogenen Stirnhörnern. Dieser sog. Carapax, der sich aus einer Hautduplikatur des Kopfes herleiten läßt, überdeckt, uhrglasförmig mit dem Rücken verschmolzen, die drei folgenden Segmente, die je ein Paar beborsteter Gliedmaßen tragen. Das erste Paar, die Antennulen, entspringen an den basalen Enden der mächtigen Oberlippe. Die beiden nächsten Paare, Antennen und Mandibeln, zeigen die für die Krebse charakteristische Spaltfußbildung mit Außen- und Innenast. Sie dienen gleichermaßen der Fortbewegung (Hüpfschwimmen) wie der Nahrungsaufnahme. Lochhead (1936) unterscheidet lange, teilweise zart gefiederte Schwimmborsten, die die Gliedmaßen ruderblattartig verbreitern, und kürzere, kräftig gefiederte Fangborsten. Letztere befinden sich nur auf den 2. Antennen und den Mandibeln, innerseits im körpernahen Bereich der Endopoditen. Sie stehen rechtwinklig abgespreizt in Richtung Labrum. Ein derber, dicker Fortsatz am antennalen Protopodit, der sog. Kiefernfortsatz, schleudert mit Hilfe starker Zinken die Nahrungspartikel dem Mundschlitz zu. Unter dem Rückenschild ragen der lange dorsale Schwanz- oder Caudalstachel und der ventrale ThoracoAbdominalanhang hervor (Abb. 1). Nach fünf Häutungen, im 6. Naupliusstadium, lassen sich auf letzterem die Anlagen von sechs Rumpfbeinpaaren erkennen. Gleichzeitig treten im Vorderkopfsegment neben dem unpaaren Stirnauge zwei seitliche Komplexaugen auf. Nach diesem Stadium, das häufig noch als "Metanauplius" bezeichnet wird, entwickelt sich mit der 6 . Häutung ein vollkommen anders gebauter Larventyp, die Cypris (Barnes, 1971; Kaestner, 1967; Krüger, 1940).

Bei der Cyprislarve (Abb. 2) - der Name weist auf die Ahnlichkeit mit einer so benannten Muschelkrebsart hin - faltet sich der Rückenschild bauchwärts ohne Gelenkspalt zu einer zweiklappigen Schale. Am hinteren ventralen Rand ragt der Thorax heraus, dessen sechs Paare einfacher Spaltfüße die Larve mit ruckartigen Bewegungen vorwärtstreiben. Das Abdomen ist stummelförmig verkürzt. Am vorderen ventralen Rand treten die beweglichen Antennulen - sie entsprechen den umgebildeten 1. 


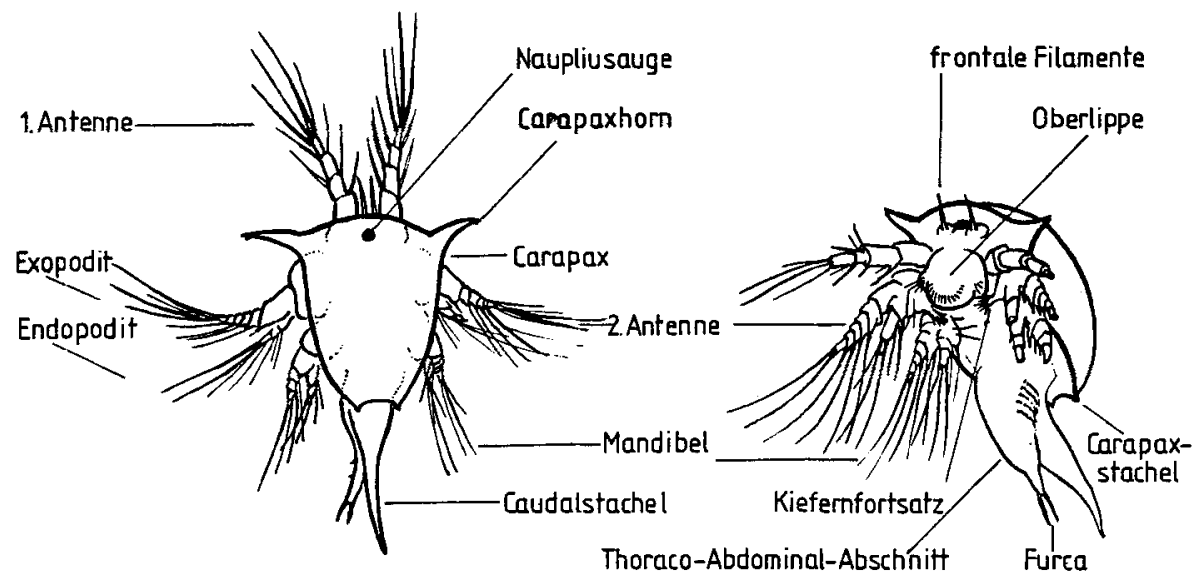

Abb. 1. Naupliuslarve. Links Rückenansicht; rechts Ansicht von schräg bauchwärts; hieruei sinđ die Borsten der linksseitigen Extremitäten nicht ausgeführt

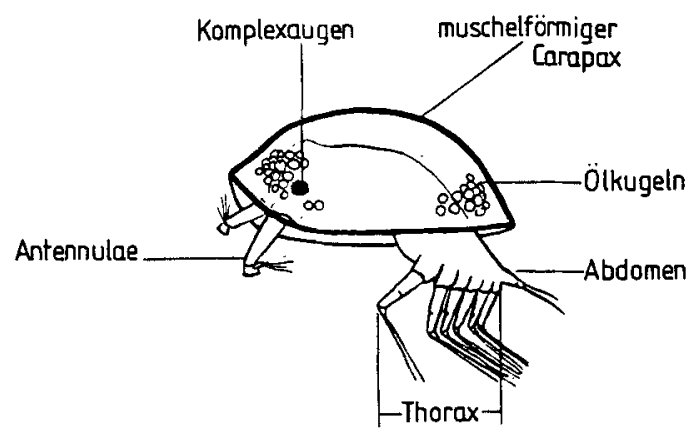

Abb. 2. Noch nicht bodenreife Cyprislarve

Antennen - hervor. Ihre zu Haftscheiben umgewandelten dritten Glieder ermöglichen dem Tier, unterstützt von Sinnesborsten, die Oberfläche eines Substrats mit stelzschrittartigen Bewegungen abzutasten, bevor es sich anheftet (Barnes, 1971; Kühl, 1953). Die 2. Antennen- und die Mandibelpaare sind völlig reduziert. Vermutlich ist letzteres noch an der Bildung der Mundwerkzeuge beteiligt. Während des Cyprisstadiums nimmt die Larve keine Nahrung auf. Sie zehrt von den Reserven, die in Form von Oltröpfchen im Vorderkopf und im Bereich des Mitteldarms gelagert sind (Kühl, 1950).

Im Gegensatz zum pelagisch lebenden Nauplius entwickelt die Cyprislarve bei vielen, meist sublitoralen Arten negativ phototaktische Reaktionen, die offensichtlich das Aufsuchen eines geeigneten Siedlungsplatzes erleichtern (Daniel, 1957; Smith, 1948; Visscher, 1928; Visscher \& Luce, 1928; Weiß, 1947; Wolf de, 1973). Strömungsstärke (Crisp, 1955; Smith, 1946) und Substratstrukturen (Crisp \& Barnes, 1954; Schäfer, 1952) stimulieren ebenfalls das Ansetzen. Das Siedlungsverhalten ist artspezifisch geprägt, wobei chemotaktische Funktionen das Muster bestimmen (Barnes \& Powell, 1950; Crisp, 1964, 1974; Crisp \& Barnes, 1954; Crisp \& Meadows, 1962, 1963; Knight- 
Jones, 1953; Larman \& Gabbott, 1975; Moyse \& Hui, 1981). Zusammengefaßte Angaben finden sich in Rainbow (1984).

\section{Metamorphose}

Hat sich die Cypris mit einem speziellen Drüsensekret der Antennulen, dem Zement, angekittet (Yule \& Walker, 1984; Walker, 1971), rundet sich der Körper ab, oder er richtet sich über der Anheftungsstelle mehr oder weniger steil in die Höhe. In dieser Ruhestellung verharrt er, bis im Schutz der Schale die Metamorphose vollzogen ist. In Abbildung 3 zeigt die untere Reihe den Umwandlungsprozeß bei Balanus improvisus

A

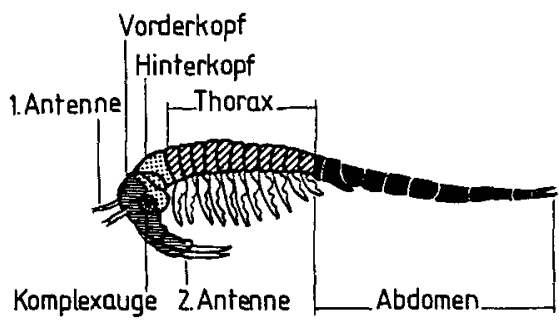

$A^{\prime}$

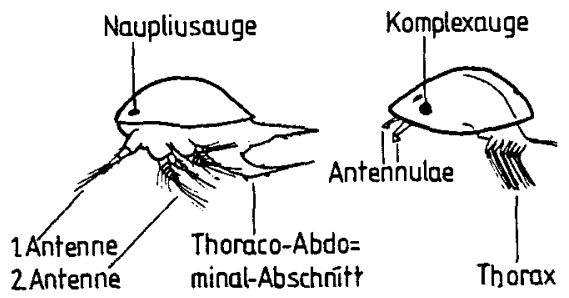

B

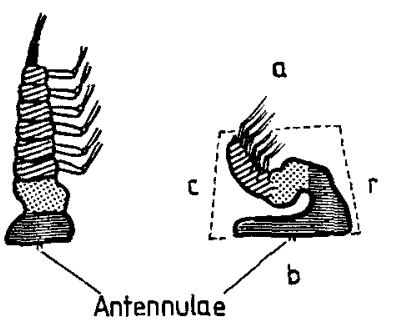

$B^{\prime}$

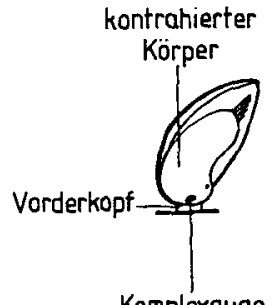

$C^{\prime}$

Larvaler Carapax

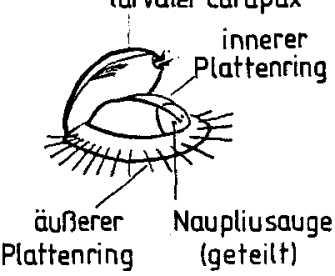

Abb. 3. Obere Reihe: Schema der Reduzierung einzelner Körperabschnitte bei einem balanomorphen Krebs im Gegensatz zu einer freischwimmenden Form (in Anlehnung an Siewing aus Remane, 1962). A freischwimmender, ursprünglich gebauter Krebs (Kiemenfußkrebs); B hypothetisches, einer angesetzten Cyprislarve in Ruhestellung entsprechendes Übergangsstadium; C eines in die Kegelform seines Gehäuses (gestrichelt) eingepaßten Balaniden; die beiden umhüllenden Mantelklappen sind nicht gezeichnet. Vorderkopf waagerecht schraffiert, Hinterkopf punktiert, Abdomen schwarz; a = apikal, $\mathrm{b}=$ basal, $\mathrm{c}=$ carinal (dem Hinterende zugekehrte Seite), $\mathrm{r}=$ rostral (dem Kopf zugekehrte Seite). Untere Reihe: Metamorphose von Balanus improvisus (nach Kühl, 1950). A' die freischwimmenden Larvenstadien: Nauplius und Cypris; B' die festgesetzte Cypris in Ruhestellung; $C^{\prime}$ die junge Seepocke nach der Metamorphose

(nach Kühl, 1950), die obere Reihe in einem hypothetischen Schema die vermutliche Umfunktionierung und Reduzierung einzelner Körperabschnitte, um die langgestreckte Gestalt einer pelagisch lebenden Form, den Larven entsprechend, in die annähernd radiärsymmetrische einer sessilen abzuwandeln (in Anlehnung an Siewing aus Remane, 1962). Nach der Umwandlung in eine fast kegelige Außenform werden zusammen mit 
der Schale Komplexaugen, Antennulensehnen und Häute der Ruderfüße abgestoßen. Der Vorderkopf ist um die Anheftungsstelle scheibenartig zur Basalfläche auseinandergeflossen. Das Naupliusauge teilt sich in zwei dunkel pigmentierte becherartige Organe, die nach beiden Seiten an die Peripherie wandern (Fales, 1928). Am Hinterrand des Vorderkopfes bildet sich eine Einschnürung, in der der aufgetriebene Hinterkopf (Prosoma) zusammen mit dem Thorax rechtwinklig abknicken, so daß die Bauchseite der Kegelspitze zugewendet liegt. Der stark verkleinerte Rumpf trägt sechs Paar Rankenfüße, die zu einer korbartigen Reuse ausgefahren werden können. Das Abdomen schrumpft zur Größe eines Höckers. An der Abknickung zwischen Vorderkopf und Prosoma entspringt eine Hautfalte, die mit zwei Lappen den Körper an beiden Flanken derart umfaßt, daß die basal gerichteten Ränder die Haftscheibe voll umwachsen und die ventralen Säume unter der Kegelspitze einen Spalt (Mantelspalt) für die Bewegung der Cirren offenhalten. Auf der äußeren Gewebeschicht dieses Mantels scheiden sich als basaler Ring vier Skelettelemente des Gehäuses ab. Ein zweiter Ring, der den Mantelrändern des Spaltes anliegt, bildet die beiden Plattenpaare, die als Deckel (Operculum) das Gehäuse an der Kegelspitze verschließen.

Die Skelettelemente sind nach der Metamorphose noch chitinös, bevor sie, nach Art verschieden, mehr oder weniger schnell verkalken. Manche Arten bilden auf dem basalen Plattenring Borsten aus, die bald wieder verschwinden. Das Operculum wölbt sich uhrglasförmig weit über den Gehäuserand empor. Unter dem größeren Deckelpaar, den Scuta, schimmern an der rostralen (der Stirn zugekehrten) Seite die Augenpunkte durch. Sie befinden sich dicht unter einer pigmentfreien Stelle des Mantelgewebes und grenzen mit ihrer Lage den rostralen Bereich ab (Krüger, 1940). Das kleinere Deckelpaar, die Terga, beschließen das Operculum an der carinalen (dem Abdomen zugekehrten) Seite. Je ein Scutum und ein Tergum sind fast miteinander verbunden, so daß sich der Mantelspalt zwischen den Paaren in Längsrichtung öffnet. Mit beginnender Verkalkung, die zuerst das Operculum erfaßt, werden die Augenpunkte immer mehr überdeckt. Der basale Plattenring, der aus einem Rostrum, einer Carina und den beiden seitlichen Lateralia besteht, erweitert sich durch zwei neue Skelettelemente, den Carinolateralia. Diese scheiden sich am carinal gelegenen Rand der Seitenplatten in Form schmaler Dreiecke ab (Abb. 4). Bei einem basalen Durchmesser von $3 \mathrm{~mm}$ ist die sechsteilige Mauerkrone vollendet (Costlow, 1956). Das hochgewölbte Operculum sinkt im Lauf des Wachstums immer tiefer in den äußeren Plattenring ein. In der Regel läuft die Metamorphose bis auf artspezifische Abweichungen nach diesem Muster ab. Runnström (1925) hat z.B. die geringfügig abgewandelte Entwicklung für Semibalanus balanoides beschrieben.

\section{Bau der adulten Seepocke}

In Anpassung an die sessile Lebensweise haben sich die Seepocken vermutlich sekundär zu Zwittern entwickelt (Walley, 1965). Die Hodenbläschen befinden sich im Prosoma, die Ovarien liegen im scheibenartigen Vorderkopf eingebettet. Die paarigen Eileiter verlaufen beiderseits des Darms und münden jeweils am basalen Glied des ersten Rankenfußes in die ventrale Mantelhöhle ein. Über den langen, biegsamen Penis, den ein benachbartes Tier durch den Mantelspalt einführt, findet die Besamung statt. Selbstbefruchtung ist nur in wenigen Fällen bekannt (Barnes \& Crisp, 1956). Der Penis entspringt an der Wurzel des Abdomens und bleibt in Ruhestellung spiralig aufgerollt 
(Abb. 5). Auch andere innere Organe haben eine Unwandlung erfahren, auf die hier nicht näher eingegangen wird.

Das Gehäuse zeigt artspezifische Merkmale, die zur Bestimmung herangezogen werden können, wenn sich das zu untersuchende Exemplar ungestört entwickelt hat (Krüger, 1927). Oft treten jedoch Verformungen durch Erosion und andere Faktoren auf.
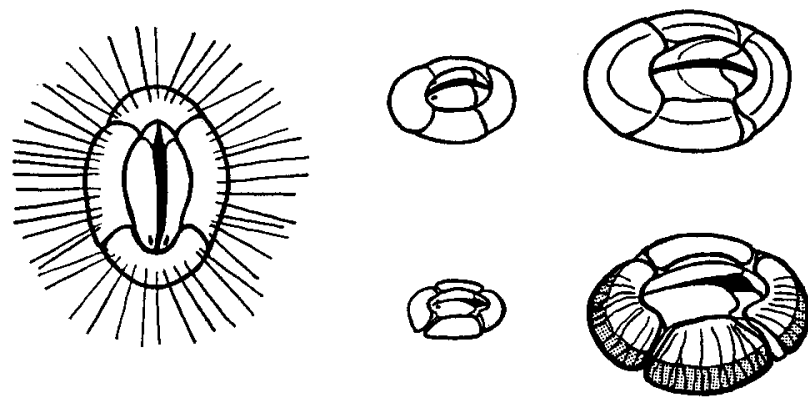

Abb. 4. Entwicklung des Gehäuses bei einigen Balaniden. Links Balanus improvisus:;Borstenstadium am ersten Tag nach der Metamorphose, basaler Durchmesser 0,7 mm (nach Costlow; 1956); Mitte Vierplattenstadium in den ersten Tagen nach der Metamorphose. Oben Semibalanus balanoides; basaler Durchmesser $1,0 \mathrm{~mm}$; die Skelettplatten sind kaum verkalkt, so daß der Tierkörper braungelb durchschimmert. Unten $B$. crenatus: basaler Durchmesser 0,7 mm; die beginnende Verkalkung läßt die Skelettplatten bläulich-milchig, jedoch noch halb durchsichtig erscheinen. Rechts Sechsplattenstadium in der dritten Woche nach der Metamorphose. Oben $S$. balanoides: basaler Durchmesser $3,1 \mathrm{~mm}$; die weißlichen, leicht braunviolett wirkenden Skelettplatten überdecken mit zunehmender Verkalkung Tierkörper und Augen; der Zuwachs ist als basaler Streifen zu erkennen. Unten B. crenatus: basaler Durchmesser 3,2 mm; trotz der zunehmenden Verkalkung zeichnen sich die Schalenröhren als weiße, senkrecht verlaufende Linien ab; der Zuwachsstreifen bleibt durchsichtiger als bei $S$. balanoides

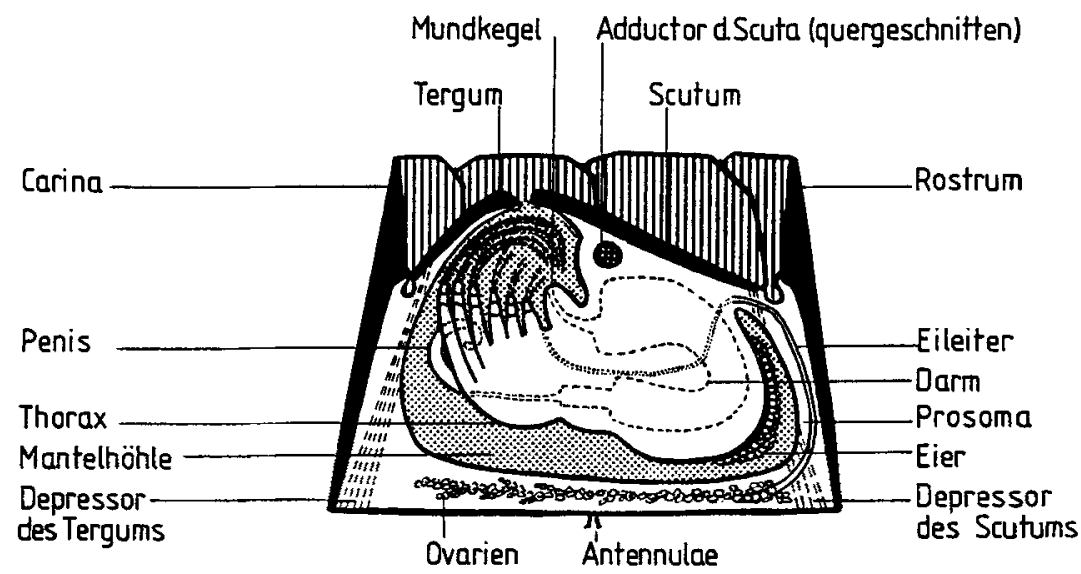

Abb. 5. Bau eines Balaniden (nach Darwin). Skelettelemente und der Vorderkopf sind in der Mittellinie geschnitten; die linke Hälfte ist entfernt. Schnittflächen der Skelettplatten $=$ schwarz; Innenseite des Gehäuses = schraffiert; Mantelhöhle = punktiert; Organe im nicht geschnittenen Hinterkopf und Rumpf $=$ gestrichelt 
Der Phänotyp wird z. B. durch Wachstumsdruck benachbarter Individuen (Gutmann, 1960), die Oberfläche des Mauerkegels durch bohrende Algen (Schäfer, 1938) und durch Abrieb verändert. In solchen Fällen läßt es sich nicht vermeiden, das Exemplar vom Substrat zu lösen, um die Basalplatte zu untersuchen oder das Operculum zur näheren Bestimmung herauszupräparieren.

Nicht alle Arten besitzen eine vom Vorderkopf abgesonderte verkalkte Basalplatte, in manchen Fällen ist sie membranös. Da die Mauerkrone den empfindlichen Tierkörper gegen Austrockung, Wasserturbulenz und Freßfeinde zu schützen hat, sind ihre Wandelemente dicht und zugleich elastisch durch übereinandergreifende, keilförmige Randabschnitte verbunden. Die bedeckenden Randteile, Radien, schieben sich über die darunterliegenden Alae, die sie artspezifisch mehr oder weniger stark überlagern (Abb. 6).
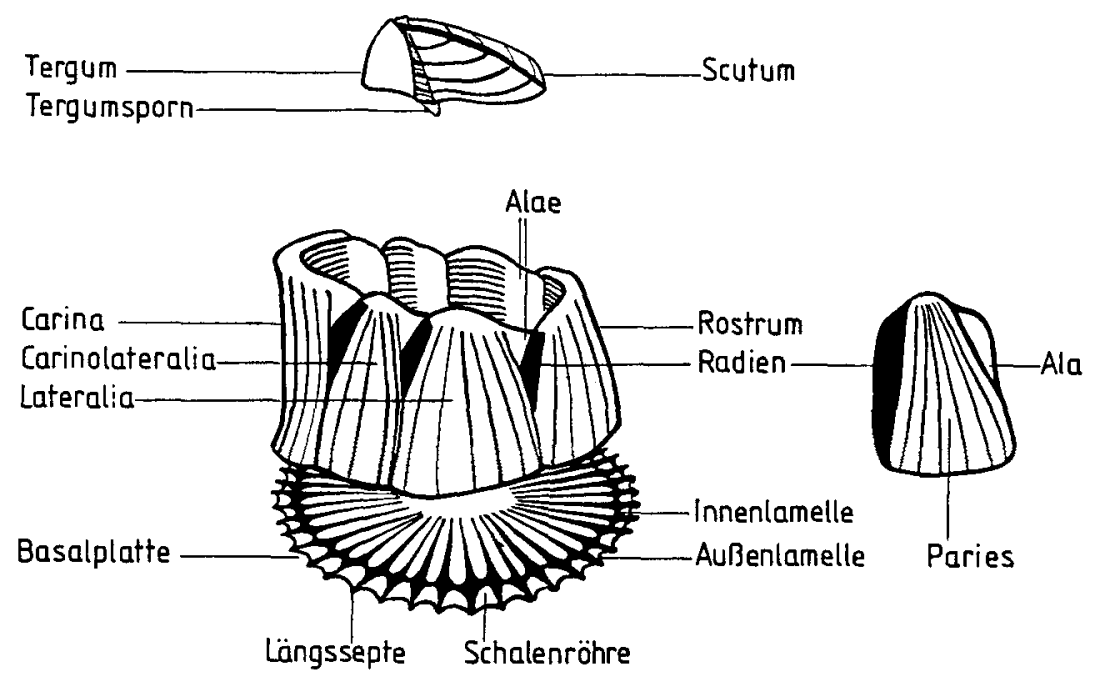

Abb. 6. Schema eines Balanidengehäuses. Mitte oben das Operculum. Mitten unten die Mauerkrone, von der Basalplatte abgehoben. Rechts eine einzelne Wandplatte. Mittelteil der Skelettplatte $($ Paries $)=$ weit längs gestreift; Alae $=$ weiß; Radien der Randplatten und Längssepten der Basalplatte $=$ schwarz

Die Mauerplatte ist, wenn sie nicht aus einer kompakten, soliden Kalkwand besteht, aus einer Außen- und Innenlamelle aufgebaut und durch Längssepten verstärkt. Die umschlossenen Hohlräume, die sog. Schalenröhren oder Kanälchen, sind von Quersepten in Etagen unterteilt. Diese kanalikulierte Struktur zeichnet sich am Rand der Basalplatte ab (Abb. 7). Bei Semibalanus balanoides füllen sich manchmal die Schalenröhren nachträglich mit Kalk aus, so daß die Mauerwand teilweise massiv erscheint. Der apikale Rand des Gehäuses ist zum Schalenring verdickt - nach Gutmann (1960) durch Apposition der Innenlamelle - der wulstartig in den Gehäuseraum hineinragt und dem Mauerkegel eine größere Stabilität verleiht. Bei dem der Brandungszone angepaßten $S$. balanoides sind die Mauerplatten und der Schalenring besonders stark ausgebildet (Barnes et al., 1970). Über die Entwicklung des Gehäuses, die Einwirkung biotischer und abiotischer Faktoren auf dessen Form berichten Crisp \& Bourget (1985). 

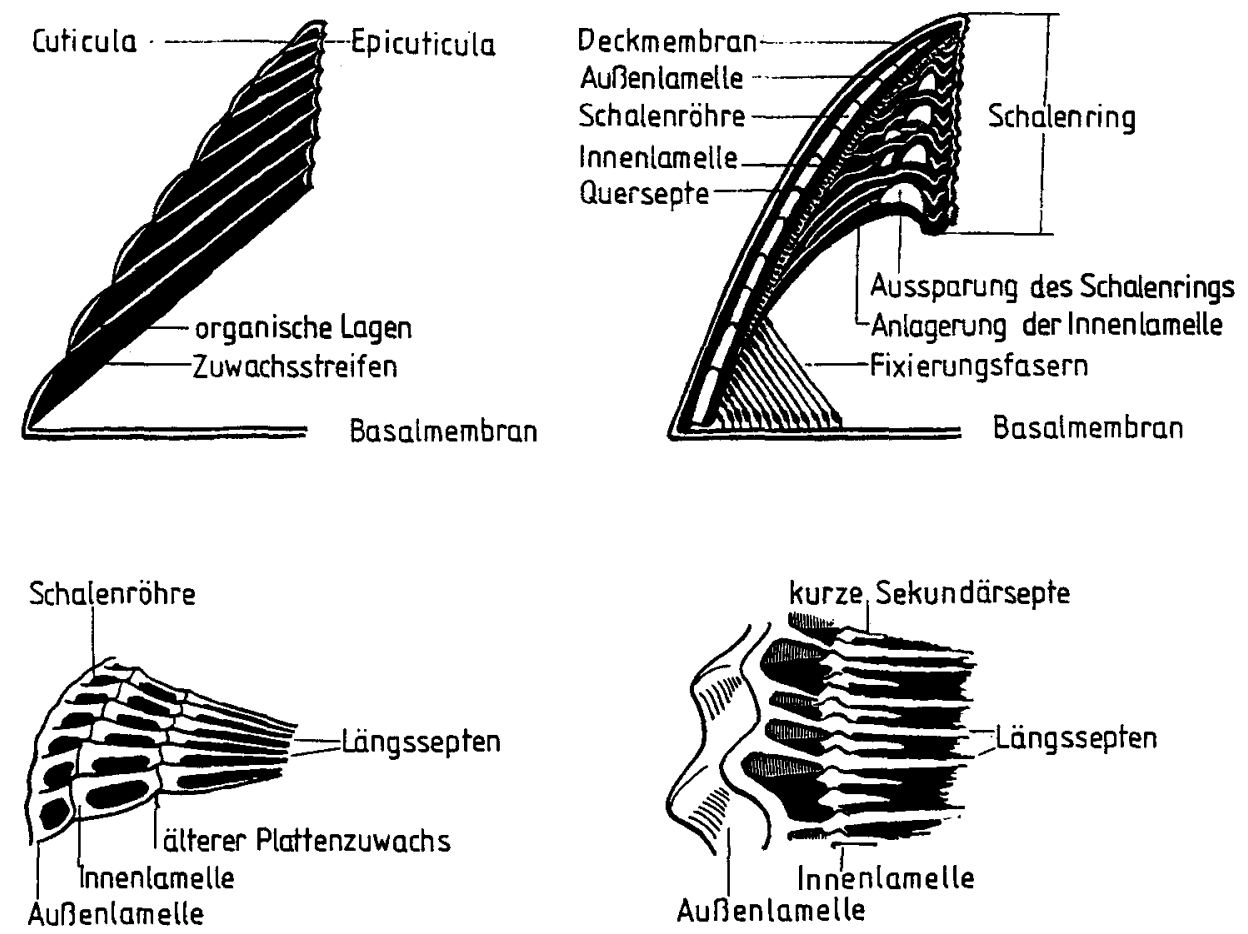

Abb. 7. Aufbau einer Mauerplatte. Links oben einschichtige Mauerplatte eines Chthamaliden (nach Bocquet-Védrine, 1963; Bourget, 1977). Rechts oben zweischichtige Mauerplatte eines Balaniden (nach Gutmann, 1960), Schnittflächen schwarz; links unten Ausschnitt aus der verkalkten Basalplatte von Balanus crenatus; rechts unten Ausschnitt aus der verkalkten Basalplatte von $B$. balanus

Die Offnung des Mauerkegels (Orificium) verschließt ein Deckel (Operculum). Er schützt das Tier vor Störfaktoren wie z. B. Freßfeinden und verhindert, daß zu viel Feuchtigkeit beim Trockenfallen verdunsten kann. Liegt der Standort längere Zeit über dem Meeresspiegel, schließt sich bei Formen im oberen Gezeitenbereich der Mantelsaum bis auf eine porenartige Offnung, der Mikropyle, durch die das Tier über den Luftsauerstoff die Atmung weiterführt (Barnes et al., 1963). Das Operculum besteht aus zwei spiegelbildlich sich gleichenden Teilen, jeder dieser Teile aus einem dreieckigen Scutum und einem hammerförmigen Tergum, die beide unbeweglich miteinander verbunden sind (Abb. 8). Zum Ausfahren der Rankenfüße öffnet sich ein Spalt zwischen den Terga und den carinal weisenden Abschnitten der Scuta, so daß das dehnbare, verschieden gefärbte Gewebe des Mantelsaums hervortritt. Ein komplizierter Muskelapparat sorgt für die Bewegung des Operculums (Gutmann, 1960). Die Scuta schließen sich durch den kräftigen Adductor, der von den Ansatzstellen quer durch das Prosoma verläuft. Die Depressoren liegen im Mantelgewebe und öffnen die Terga durch Zug basalwärts (vgl. Abb. 5). 

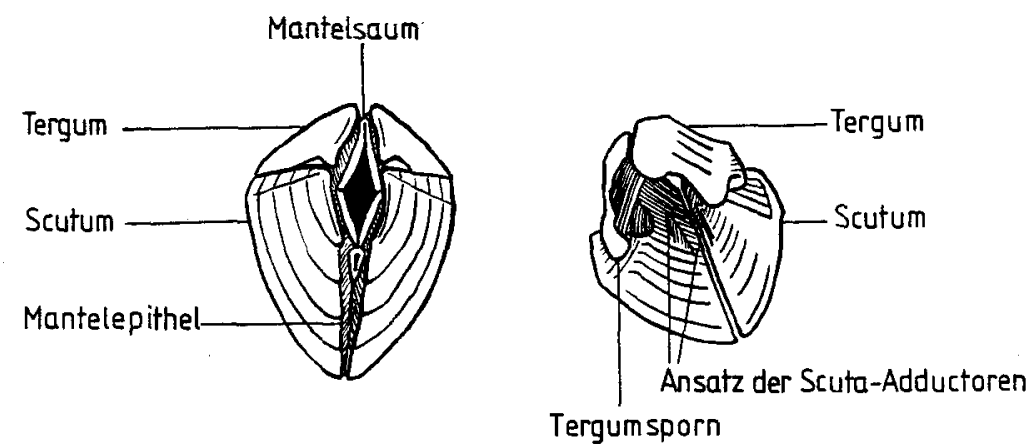

Abb. 8. Die Skelettplatten des Operculums. Links Außenansicht. Rechts Innenansicht nach Entfernung des Mantelgewebes, von schräg unten gesehen

\section{BESTIMMUNG DER ARTEN}

Die im deutschen Nord- und Ostseebereich lebenden Balanidenarten siedeln in der Gezeitenzone des Wattenmeeres und an der Felsküste Helgolands oder werden im Angespül und Beifang der Fischer gefunden. Systematisch sind sie wie folgt einzuordnen:

\section{System}

(Newman \& Ross, 1976)

\section{Unterklasse Cirripedia \\ Ordnung Thoracica \\ Unterordnung Verrucomorpha}

Familie Verrucidae

Verruca stroemia (Müller) (Seewarze)

Unterordnung Balanomorpha

Familie Chthamalidae

Chthamalus stellatus (Poli) (Sternseepocke)

Familie Archaeobalanidae

Elminius modestus Darwin (Australseepocke)

Semibalanus balanoides (L.) (Gezeitenseepocke)

Familie Balanidae

Balanus balanus (L.) (geschnäbelte Seepocke)

$B$. crenatus Bruguière (gekerbte Seepocke)

B. improvisus Darwin (Brackwasserseepocke)

\section{Wuchsformen}

Am eindeutigsten sind die Bestimmungsmerkmale an den Exemplaren zu erkennen, die über genügend Raum zu einem ungestörten Wachstum verfügen und einen mehr oder weniger gleichmäßigen Gehäusekegel entwickeln, der sog. Patellaform. Diese kann durch das Relief des Untergrundes abgewandelt werden (Gutmann, 1962). 
Siedeln die jungen Seepocken jedoch so eng, daß sich die Basalplatten nicht mehr auszudehnen vermögen, wachsen die Gehäuse wie Türme senkrecht in die Höhe (Schäfer, 1952), wobei die Mauerplatten der Einzelindividuen teilweise mit denen der benachbarten Tiere verschmelzen. Damit gehen artspezifische Merkmale der Gehäusewand verloren und die Bestimmung stützt sich ausschließlich auf die Struktur des Operculums und der Basalplatte (Abb. 9). Nach den gleichen Gesichtspunkten muß bei
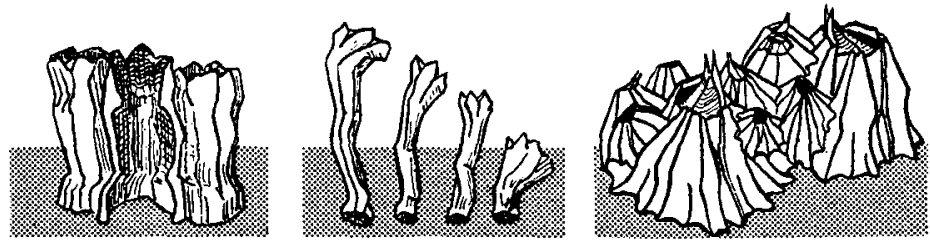

Abb. 9. Wuchsformen der Balaniden bei dicht siedelnden Tieren. Links Turmwachstum bei Semibalanus balanoides (keine verkalkte Basalplatte); der basale Durchmesser entspricht der Weite der Gehäuseöffnung. Mitte Buckelwachstum bei Balanus crenatus (gekennzeichnet durch eine verkalkte Basalplatte); der basale Durchmesser ist weitaus geringer als die Weite der Gehäuseöffnung; die Kelchform der Einzeltiere, es sind vier Beispiele herausgegriffen, verändert sich je nach dem Standort innerhalb der Buckelkolonie; im Zentrum befinden sich die höchsten und gestrecktesten; nach dem Rande zu werden die Kelche niedriger und biegen sich immer stärker zur Peripherie hin um. Rechts Knäuelwachstum bei $B$. balanus. Bis zu drei Generationen siedeln aufeinander, wobei jedoch die Opercularöffnungen frei bleiben

der Bestimmung der Seepocken einer sog. Buckelkolonie verfahren werden. In dieser erweitern sich die Gehäuse von der schmalen Basis aus kelchartig, wobei im Gegensatz zur Turmkolonie der Durchmesser der Gehäuseöffnung den der Basis weit übertrifft. Die damit verbundene Vergrößerung der Buckeloberfläche bewirkt, daß sich die Kelche vom Zentrum der Kolonie nach dem Rande zu immer stärker nach außen umbiegen (Barnes \& Powell, 1950). Eine weitere Wuchsform ist für Balanus balanus (Gutmann, 1961) und $B$. crenatus charakteristisch, das Knäuelwachstum. Hierbei siedeln Jungtiere oft zu mehreren Generationen auf Adulten und es entsteht der Eindruck eines kleinen, unregelmäßigen Kalkriffs. So dicht jedoch die juvenilen auf den Gehäusen der Alttiere sitzen, die Beweglichkeit der Operkularplatten bleibt für die Cirrentätigkeit erhalten (Schäfer, 1952).

Der nachfolgende BestimmungsschlüsseI läßt sich auch für Wuchsformen verwerten, die nicht zum Patella-Typ gehören, sofern Operculum und Basalplatte gut erhalten sind. Haben äußere Einflüsse die charakteristischen Formen und Grenzlinien auch dieser Skelettelemente verwischt, können Feinstrukturen zur Bestimmung herangezogen werden wie z. B. der Aufbau der Mauerplatten. Diese sind bei Chthamalus stellatus einschichtig, bei Semibalanus balanoides und anderen Balaniden dagegen zweilamellig gebildet (Abb. 7 oben). Es muß jedoch berücksichtigt werden, daß bei mehrjährigen Individuen von $S$. balanoides die Schalenröhren im basalen Teil des Gehäuses nachträglich mit Kalk ausgefüllt sein können, so daß er einschichtig erscheint. Im apikalen Teil dagegen, der sich zu Beginn des Wachstums entwickelt hat, ist die Zweilamellenstruktur erhalten geblieben. 
Abb. 10

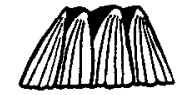

Abb. 11

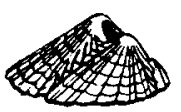

Abb. 12

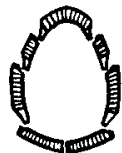

Abb. 13

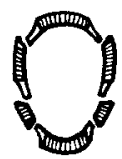

Abb. 14

Abb. 15

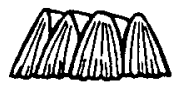

Abb. 16
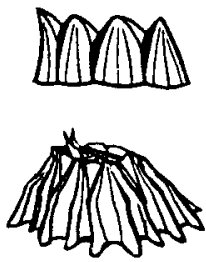

\section{Bestimmungsschlüssel}

1 Gehäuse bilateral mit jederseits annähernd gleichmäßig ausgebildeten Wandplatten (Abb. 10)

- Gehäuse deutlich asymmetrisch mit 4 unterschiedlich ausgebildeten Platten (Abb. 11)

Familie Verrucidae

2 Mauerkegel sechsplattig

- Mauerkegel vierplattig, Platten massiv

3 Rostrum des Mauerkegels breit mit 2 seitlichen Radien (Abb. 12), Platten zweilamellig

Familie Archaeobalanidae und Balanidae

- Rostrum des Mauerkegels schmal mit 2 seitlichen Alae (Abb. 13), Platten massiv, einlamellig

Familie Chthamalidae

4 Archaeobalanidae und Balanidae Mauerkegel gleichmäßig, nicht steil ansteigend (Abb. 14)

- Mauerkegel steil, mehr oder weniger karinal überkippend (Abb. 15)

5 Mauerplatten mit tiefen, senkrecht verlaufenden Scharten (Abb. 14) oder Rippen (Abb. 16) und mehr oder weniger tief gebuchtetem Basalrand

- Mauerplatten überwiegend glatt mit meist ungebuchtetem Basalrand, bei älteren Exemplaren auch flach längs gefaltet, durch Erosion wird die kanalikulierte Struktur sichtbar (Abb. 15)

6 Radien und Alae stark abgeschrägt, so daß der Rand des Gehäuses tief gekerbt erscheint (Abb. 15)

- Radien und Alae wenig abgeschrägt, so daß der Rand des Gehäuses annähernd glatt erscheint (Abb. 10, 14, 17)

7 Radien schmal mit gerauhtem Rand, fast bis zur (6) 9Basis reichend (Abb. 15)
(1) 3

(1) 22

(5-) 7 
Abb. 17

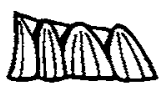

Abb. 18

Abb. 19

Abb. 20

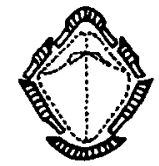

8 Radien sehr breit, nicht abgeschrägt, die Alae vollkommen überdeckend (Abb. 10)

- Radien fast oder ganz reduziert, Alae bleiben im apikalen Teil des Gehäuses als kleine Dreiecke sichtbar (Abb. 14)

9 Gehäuseöffnung in Relation zur Basis weit, breit rhombisch, größte Weite fast in der Mitte der Medianlinie (Abb. 18)

- Gehäuseöffnung weit, spitz rhombisch mit carinal deutlich ausgezogener Spitze (Abb. 19)

10 Gehäuseöffnung in Relation zur Basis eng, spitz rhombisch bis oval (Abb. 20)

Abb. 21

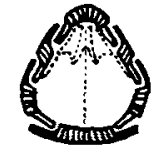

Abb. 22

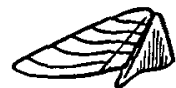

- Gehäuseöffnung eng, dreieckig (Abb. 21)

11 Deckelplatten mehr oder weniger dicht zusammenschließend (Abb. 22)

Abb. 23

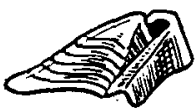

- beide Terga durch eine nach unten gebogene Seitenkante (interapikale Area) von den Scuta getrennt (Abb. 23), Deckel in der Medianlinie dachfirstartig aufgewölbt

Abb. 24

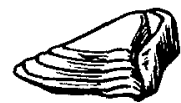

Abb. 25

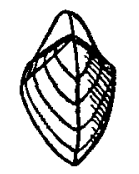

Abb. 26

Abb. 27
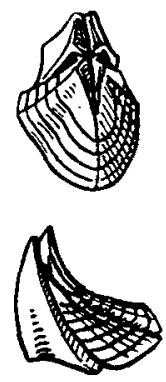

12 Spitze (Apex) jeder Platte abgerundet, Platten in den Nähten flach aneinanderstoßend (Abb. 24)

- Apices der Deckelplatten nicht gerundet, nicht auseinanderweichend, Deckel flach bis schwach uhrglasförmig gewölbt (Abb. 25)

13 spitz geformte Apices deutlich auseinanderstre- (11-) 15 bend, reversartig umgeschlagen (Abb. 26)

- Apices der Terga schnabelartig ausgezogen, über den Gehäuserand herausragend (Abb. 27)

14 Quernaht des Deckels geradlinig, in spitzem Winkel auf den Längsspalt stoßend (Abb. 25)
$(6-) 10$

(5) 10

(5) 9

(8-) 12

(7) $11-$

$(7-) 11$

(8) $13-$

(10) 12

(9) 13

(9) 14-

(11) 14

(10-) 20

(12-) 15- 
Abb. 28

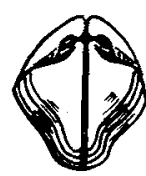

Abb. 29

Abb. 30

Abb. 31

Abb. 32
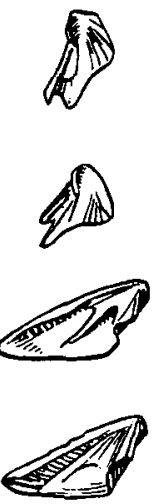

17 Mantelsaum rund um den Längsspalt weißlich, gelegentlich mit dunklen Querbändern

- Mantelsaum rund um den Längsspalt mit mehrfarbigen Bändern: gelb, purpurn bis braun, und einem die Deckel berührenden gelben Rand

18 weißer Mantelsaum mit braunem Mittelfleck, gelegentlich àuch einer schwachbraunen Zeichnung am rostral gelegenen Rand

- weißer Mantelsaum mit 3 dunkelpurpurnen Querbändern

19 Basalplatte verkalkt

- Basalplatte membranös

Semibalanus balanoides (Abb. $44 \mathrm{a}-\mathrm{c}$ )

20 Mauerplattenstruktur am Rande der Basalplatte deutlich als äußere und innere Lamelle erkennbar, die zusammen mit den Längssepten das Lumen der Schalenröhren (Kanälchen) umfassen (Abb. 33)

- innere Wandlamelle zusätzlich mit kurzen, in das Lumen der Schalenröhren hineinreichenden, sekundären Längssepten gekennzeichnet (Abb. 34) Balanus balanus (Abb. $44 \mathrm{a}, \mathrm{b}, \mathrm{d}$ )
(17-) 20

(12) 18

(13) $16-$

(14) 16

(15-) 17

(15) $17-$

(16) 18

(16-) 19

(14-) 19

(17) 21

(19) 21-

\section{(13-)}

Abb. 34

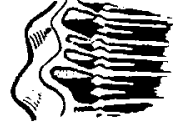


Abb. 35

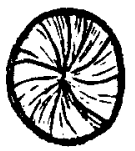

21 verkalkte Basalplatte porös mit kräftigen radialen

(18-) Rippen oder Längssepten, die in Stromrichtung gedreht sein können (Abb. 35)

Balanus improvisus (Abb. 44 a-d)

Abb. 36

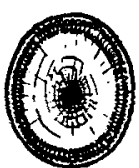

- verkalkte Basis massiv, so dünn, daß das Substrat hindurchschimmert und die Ansatzstelle der Cypris als Loch erscheint oder so kompakt, daß die radialen Rippen verwischt sind und'sich die Wachstumsschübe der Wandlamellen nur nach dem Rande zu als konzentrische Ringe abheben (Abb. 36)

Balanus crenatus (Abb. 44 a-d)

Abb. 37

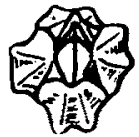

Abb. 38

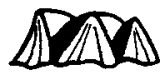

Abb. 39

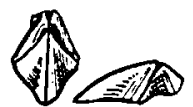

224 Gehäuseplatten, jede mit 2 kräftigen Falten versehen, so daß der Basisrand einen achtstrahligen Stern ergibt (Abb. 37). Gehäuseplatten glatt, zweilamellig, jedoch massiv und nicht kanalikuliert, Radien und Alae breit mit gebogenen Rändern (Abb. 38). Gehäuseöffnung spitz rhomboid, Querfurche des Deckels mit jederseits schmalen, spitzdreieckigen, dunkelgrauen Areae (Abb. 39), Mantelsaum weiß, orangefarbener Mittelfleck, Basis membranös

Elminius modestus (Abb. $44 \mathrm{a}-\mathrm{c}$ ) Nach dem 2. Weltkrieg in die Nordsee eingeschleppt, Konkurrent für $S$. balanoides und $B$. crenatus

Abb. 40

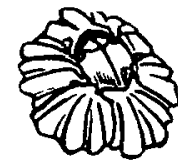

Abb. 41

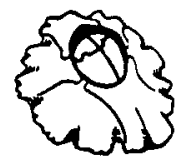

23 Chthamalidae

Gehäuseöffnung deltaoid=drachenförmig (Abb. 40)

bei älteren Exemplaren mehr gerundet (Abb. 41), Wandplatten einlamellig, Radien reduziert, Alae deutlich, doch sind bei alten Tieren die Plattengrenzen meist verwischt, Apices der Deckelplatten eingeebnet, Querfurche des Deckels beiderseits geschwungen, sie steht senkrecht zum Längsspalt (bei $S$. balanoides spitzwinklig), Basis membranös

Chthamalus stellatus (Abb. 46 a-b)

Auf Helgoland einmal (jedoch nicht mit Sicherheit) nachgewiesen. 
Abb. 42

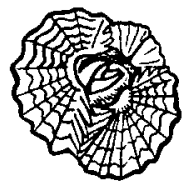

Abb. 43

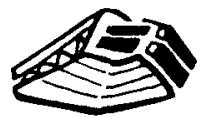

24 Verrucidae

Gehäuse abgeplattet, aus 4 längsgefurchten unterschiedlich großen .und geformten Gehäuseplatten bestehend (Abb. 42): einem großen Rostrum, einer nur wenig kleineren Carina und zwei sehr kleinen, starr in die Mauerkrone eingefügten Opercularplatten, ableitbar als ein Scutum und ein Tergum. Die beiden kleinen Mauerplatten stehen im Gegensatz zu den großen steil aufgerichtet, was die Asymmetrie des Gehäuses betont. Die beweglich gebliebene zweite Deckelhälfte knickt im rechten Winkel ab und öffnet in der Funktion des Operculums den Mantelspalt seitlich am Mauerrand längs der beiden, starr in die Gehäusewand eingebauten Deckelelemente (Abb. 43, Scuta und Terga schwarz ausgeführt). Basalplatte membranös

Verruca stroemia (Abb. 48 a-b)

Auf Helgoland nicht selten, gelegentlich auch im Gezeitenbereich an Steinen zu finden.

Auf weitere allgemeine Bestimmungsliteratur sei verwiesen: Broch (1924), Campbell (1977), Kolosváry (1939, 1941), Krüger (1927), Newman \& Ross (1976), Southward (1976), Southward \& Crisp (1965).

\section{Familie Archaeobalanidae}

Elminius modestus (Abb. 44)

(a) Gehäuse vierplattig, basaler Durchmesser 5-10 mm, Gehäuse carinal spitz ausgezogen, carinal höher als rostral, Skelettplatten glatt, grau, mit je zwei Längswülsten, so daß der Basisrand einen achtstrahligen Stern ergibt, Radien dick, mäßig breit, apikal stark abgeschrägt und basal spitzwinklig verlaufend, Alae dünn, breit-dreieckig, am oberen Gehäuserand wenig abgeschrägt, Mauerplatten zweischichtig, jedoch nicht kanalikuliert, so daß die Wand massiv erscheint, Deckel schwach gewölbt, Mantelsaum weiß mit einem orangefarbenen oder braunen Fleck in der Mitte (vgl. Southward \& Crisp, 1963). (b) Scuta entlang der Mittellinie gewölbt, ihre tergalen Ränder stoßen in der Mittellinie spitzwinklig zusammen, zwischen Scutum und Tergum jederseits eine schmal-dreieckige, grau gefärbte Area, Apices der Terga spitz, sie weichen geringfügig auseinander. (c) Terga mit undeutlich ausgebildetem Sporn, triangelförmig, Basalplatte membranös, extrem dünn (nicht abgebildet).

\section{Semibalanus balanoides (Abb. 44)}

(a) Gehäuse sechsplattig, basal gebuchtet, basaler Durchmesser bis zu $15 \mathrm{~mm}$, kegelig mit längsgefurchten Skelettplatten, Radien schwach entwickelt, meist rudimentär, die nur wenig abgeschrägten Alae bleiben am oberen Gehäuseabschnitt als kleine, breite Dreiecke sichtbar, Mauerplatten kanalikuliert, jedoch sind die Schalenröhren im basalen Abschnitt gelegentlich sekundär mit Kalk ausgefüllt, so daß dort die Wand massiv erscheint, Gehäuseöffnung weit, breit-rhombisch geformt mit größter Breite in Höhe der halben Mittellinie, Scheitel der Opercularplatten gerundet, Mantelsaum weiß mit mittlerem, braunen Fleck, manchmal auch mattbrauner Zeichnung (vgl. Southward \& Crisp, 1963). (b) Opercularhälften schließen beim mehrjährigen Individuum flach und 
Elminius modestus

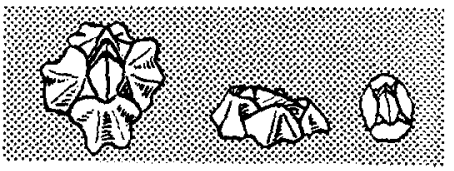

a

Semibalanus balanoides

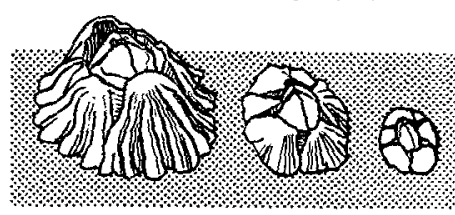

a

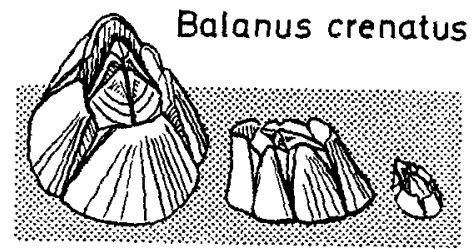

a

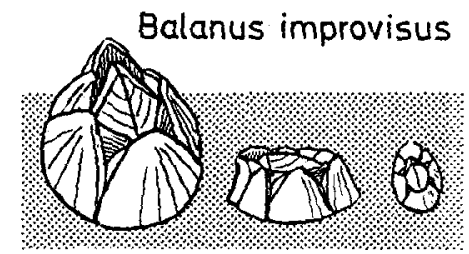

a

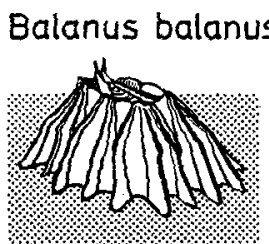

a

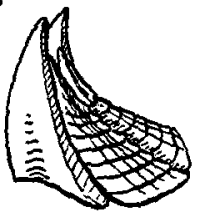

b

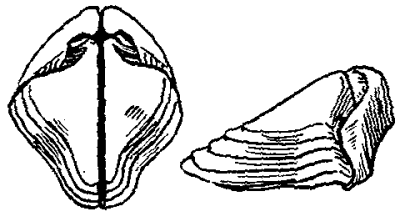

b

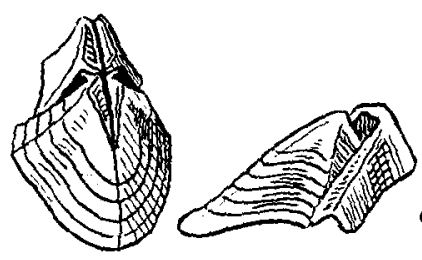

b
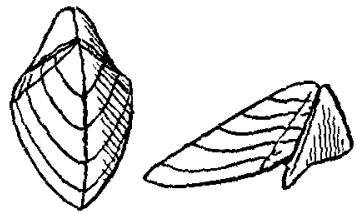

b

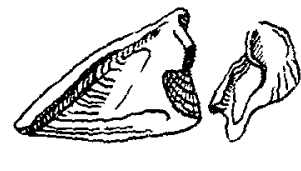

c c
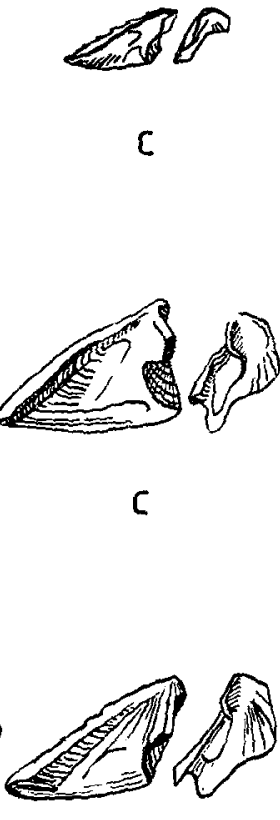

c

\section{B.crenatus Bimprovisus B.balanus}
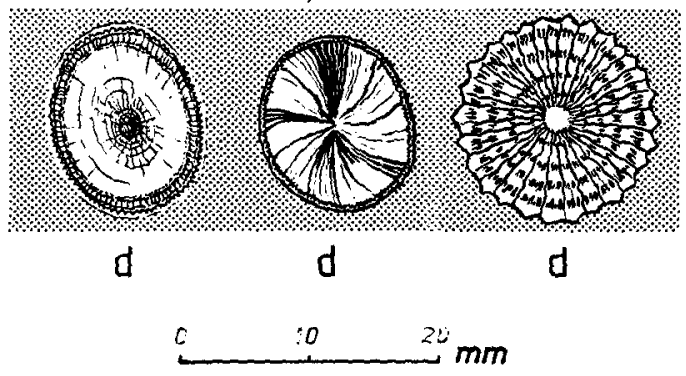

Abb, 44. Seepockenarten der deutschen Wattgebiete. $a=$ adultes Tier, daneben je ein juveniles nach fünf und nach zwei Monaten; $b=$ Operculum, Ansichten von oben und von der Seite; $c=$ Scutum und Tergum, Innenseiten; $d$ = Basalplatten der Arten mit verkalkter Basis 
fugenlos zusammen, Fuge zwischen Scuta und Terga sinusartig geschwungen, die Bögen beider Seiten stehen im spitzen Winkel auf der Mittellinie (vgl. Southward \& Crisp, 1963). (c) Scutum auf der Innenseite ohne Adduktorkrista, Sporn der Terga stumpf gerundet, von der basalen Kante weit abweichend und diese nicht überragend. Basalplatte membranös (nicht abgebildet). - Bei großer Besiedlungsdichte entwickelt sich Turm- und Buckelwachstum (Abb. 9), jedoch nie ein Knäuelwachstum. Höhe der Turmkolonien 2-3 cm, dabei entspricht der Durchmesser der Basalplatte dem der Gehäuseöffnung, die Mauerplatten sind dünner als beim isolierten Tier und nicht mehr gefurcht, mit denen der benachbarten Individuen verschmolzen. Die gleichen Merkmale gelten für Buckelkolonien, doch ist bei ihnen die Weite der Gehäuseöffnung wesentlich größer als der Umfang der Basalplatte. Nur in Ausnahmefällen, z. B. bei hohem Siedlungsdruck, setzen sich Junge auf Adulten an, wobei sie mit dem Wachstum der letzteren die Gehäusewand hinaufgeschoben werden, es entsteht aber nie die typische Knäuelform.

\section{Familie Balanidae}

Balanus crenatus (Abb. 44)

(a) Gehäuse sechsplattig, basaler Durchmesser bis zu $20 \mathrm{~mm}$, steilkegelig, carinal leicht überkippend mit glatten, bei älteren Tieren auch längsgefurchten Skelettplatten, Radien schmal mit gerauhten Rändern, fast bis zur Basis des Gehäuses reichend, ebenso wie die Alae stark abgeschrägt, so daß der Gehäuserand tief gekerbt erscheint, Mauerplatten zweilamellig, kanalikuliert, Schalenröhren jedoch nie nachträglich mit Kalk ausgefüllt, Gehäuseöffnung weit, spitz-rhombisch mit carinal ausgezogener Spitze, Deckel carinal ausgezogen, Opercularplatten mit spitzen, auseinanderstrebenden Scheiteln, Mantelsaum gelb bis blaßgelb mit braunem Längsband, entlang der Deckelplatten gelb gesäumt (vgl. Southward \& Crisp, 1963). (b) Opercularhälften in der Mitte gegeneinander aufgewölbt, Furche zwischen Scuta und Terga verläuft spitzwinklig zur Mittellinie und ist deutlich als interapikale Area ausgebildet. (c) Scutum auf der Innenseite ohne Adduktorkrista, Sporn der Terga etwas schlanker als bei Semibalanus balanoides, die basale Kante nicht überragend. (d) Basalplatte oft dünn mit Zuwachsstreifen, die am Rand als konzentrische Ringe erkennbar sind, oft so stark verkalkt, daß die konzentrischen Ringe verschwimmen und die Innenfläche glatt, kompakt und durch kaum angedeutete radiale Rippen (Längssepten) gegliedert wirkt. - Bei großer Besiedlungsdichte entwickelt sich Turm-, Buckel- und Knäuelwachstum, Höhe der Buckelkolonien 4-5 cm; Knäuelformen können stark ausgeprägt sein (Abb. 9).

\section{Balanus improvisus (Abb. 44)}

(a) Gehäuse sechsplattig, basaler Durchmesser bis $15 \mathrm{~mm}$, Kegel niedriger und nicht so steil wie bei $B$. crenatus, Skelettplatten glatt, Radien schmal, abgeschrägt mit glatten, leicht gebogenen Rändern, die bis zur halben Gehäusehöhe hinabreichen, Alae kaum abgeschrägt, so daß der Gehäuserand nicht gekerbt erscheint, Mauerplatten zweilamellig, kanalikuliert, Schalenröhren jedoch nie sekundär mit Kalk ausgefüllt, Gehäuseöffnung rhombisch, wesentlich enger als bei $B$. crenatus, nicht kielartig ausgezogen, Deckel schwach uhrglasförmig gewölbt, Mantelsaum weißgrundig mit jederseits drei dunklen Querbändern (vgl. Southward \& Crisp, 1963). (b) Opercularplatten schließen dicht zusammen, Apices streben nicht auseinander, Furche zwischen Scuta und Terga 
verläuft spitzwinklig zur Mittellinie. (c) Scutum auf der Innenseite mit deutlich ausgeprägter Adduktorkrista, Tergum stumpf mit langem schmalen Sporn, der die basale Kante weit überragt. (d) Die Basalplatte wirkt weniger kompakt als die von $B$. crenatus, besitzt jedoch stark verkalkte radiale Rippen, die in Richtung des Wasserstroms gedreht sein können. - Bei großer Besiedlungsdichte entwickelt sich ein meist nur schwach ausgeprägtes Turmwachstum, ein Aufeinandersitzen kommt nur in Ausnahmefällen vor.

\section{Balanus balanus (Abb. 44)}

(a) Gehäuse sechsplattig, basaler Durchmesser bis zu $50 \mathrm{~mm}$, Skelettplatten mit stark hervortretenden, kantigen Längsrippen, breit-dreieckigen Radien, die die Alae vollkommen überdecken, nicht abgeschrägt, so daß der obere Gehäuserand relativ glatt erscheint, Mauerplatten zweilamellig, kanalikuliert, Innenlamelle durch kurze Sekundärsepten verstärkt, Gehäuseöffnung sehr eng, dreieckig geformt, Scheitel der tergalen Opercularplatten bogig ausgezogen, den oberen Gehäuserand weit überragend, Mantelsaum rund um den Längsspalt gelb-braun und weiß gestreift (vgl. Southward \& Crisp, 1963). (b) Opercularplatten schließen dicht zusammen, Apices sind lang und spitz, bei den Terga vogelschnabelartig gebogen und etwas auseinanderweichend. Da die Innenseiten der Opercularplatten keine herausragenden charakteristischen Merkmale aufweisen, sind diese nicht abgebildet. (d) Basis im allgemeinen stark verkalkt, Rand spitz gebuchtet, Längssepten kräftig ausgebildet, zwischen sie schieben sich im Bereich der Innenlamelle kurze Sekundärsepten (Abb. 7). Kein Turmwachstum, jedoch ein kalkriffartig ausgebildeter Knäuelwuchs (Abb. 9).

\section{Familie Chthamalidae}

Bei flüchtiger Betrachtung sind die Gezeitenformen Semibalanus balanoides und Chthamalus stellatus leicht zu verwechseln, doch weisen die Gehäuse der Chthamalidae (Abb. 45) aufgrund ihrer phylogenetischen Herkunft markante Unterschiede auf. Die Sechszahl der Mauerplatten läßt sich auf ein Reduzieren und Verschmelzen verschiedener Skelettelemente zurückführen, die bei heute noch lebenden mehrplattigen Arten (z. B. Octomeris sp., Kapland) in der ursprünglichen Form erhalten blieben. Die Herkunft der reduzierten Platten jedoch, erkennbar an Radien und Alae, ist bei beiden Spezies anders abzuleiten. Darauf beruht auch die unterschiedliche Ausbildung der Gehäuseöffnungen.

\section{Chthamalus stellatus (Abb. 46)}

(a) Gehäuse sechsplattig, sehr variabel, basaler Durchmesser bis zu $12 \mathrm{~mm}$, die in der Nordsee anzutreffende Variante ist niedrig konisch geformt, bei dichter Besiedlung auch höher kegelig, die Skelettplatten können glatt oder mehr oder weniger deutlich gefaltet sein, sie wirken gleich groß, da das Rostrum im Gegensatz zu Semibalanus balanoides aus einem einzigen Wandelement besteht, Radien reduziert, Alae dagegen am oberen Gehäuserand gut sichtbar. Mauerplatten nur aus einer soliden Kalkwand aufgebaut, Gehäuseöffnung bei Jungtieren drachenförmig, bei älteren Exemplaren zu einem fast kreisförmigen Oval erweitert, gleichzeitig werden die Längsfalten eingeebnet und die Grenzen zwischen den Mauerplatten verwischt. Die Deckelplatten schlieBen dicht zusammen, ihre Apices sind eingeebnet, die Furche zwischen Scuta und Terga 
steht senkrecht auf der Mittellinie, sie ist nach dem Gehäuserand zu sinusartig geschwungen, Mantelsaum hell bis stahlblau mit orangefarbenem Fleck in der Mitte und braunen Zonen an den rostralen und carinalen Enden (vgl. Southward \& Crisp, 1963), Basis membranös. (b) Die Form des Scutums umschreibt ein fast gleichseitiges Dreieck, die Kanten entlang des Mantelspaltes bilden mit der carinalen Kante einen rechten Winkel (Kolosváry, 1939), die Ansatzmulde für den Adduktor ist besonders tief, das breite Tergum besitzt einen abgerundeten Apex, der Sporn ist kaum entwickelt.

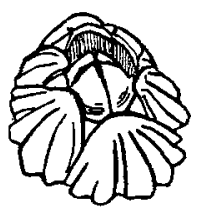

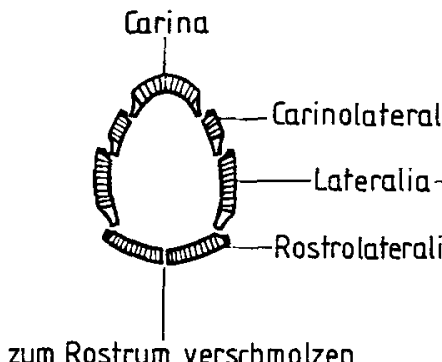

zum Rostrum verschmolzen
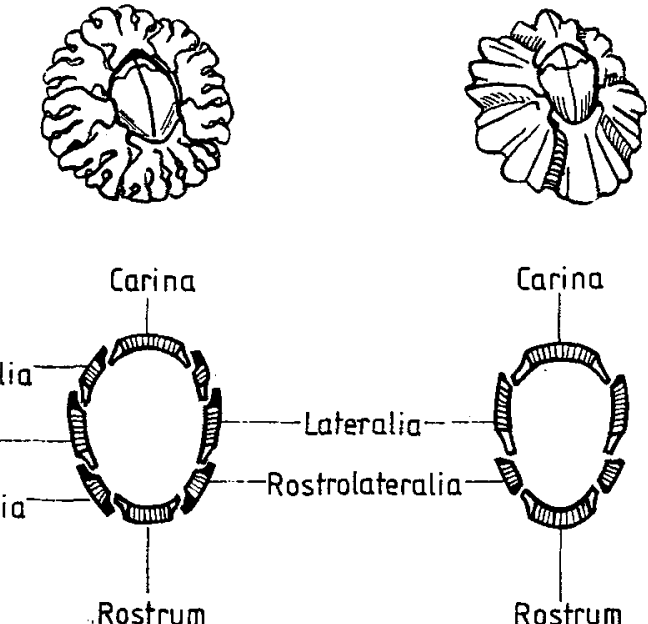

Abb. 45. Homologie der Skelettplatten (nach Darwin, 1854). Links sechsplattige Form von Balanus. Das aus zwei verschmolzenen Rostrolateralia èntstandene Rostrum ist breit und besitzt beiderseits Radien; Gehäuseöffnung eiförmig bis breit rhomboid. Mitte achtplattige Form von Octomeris; Rostrum schmal mit beiderseits Alae, Rostrolateralia mit je zwei Radien, Gehäuseöffnung oval bis rund. Rechts sechsplattige Form von Chthamalus, Rostrum schmal mit beiderseits Alae, Rostrolateralia mit je zwei Radien, Carinolateralia reduziert, Gehäuseöffnung deltaoid, größte Breite carinal verschoben. Skelettplatten der Schemata $=$ gestreift; Radien $=$ schwarz; Alae $=$ wei $\beta$

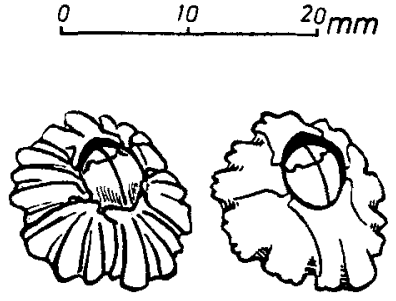

a
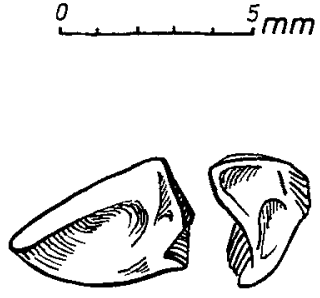

b

Abb. 46. Chthamalus stellatus. a links junges; a rechts älteres Exemplar mit korrodierter Gehäuseoberfläche; b Innenseite von Scutum und Tergum (nach Kolosváry, 1939) 


\section{Familie Verrucidae}

Vermutlich haben sich die Verrucomorpha neben den Balanomorpha als selbständiger Zweig entwickelt. Durch die Asymmetrie des Gehäuses und die für diese Unterordnung typische Reduktion der Skelettelemente nehmen sie schon äußerlich eine Sonderstellung ein (Broch, 1924). Die vier, in Form und Größe völlig unterschiedlichen Gehäuseplatten lassen sich als ein umfangreiches Rostrum, eine fast gleich große Carina und

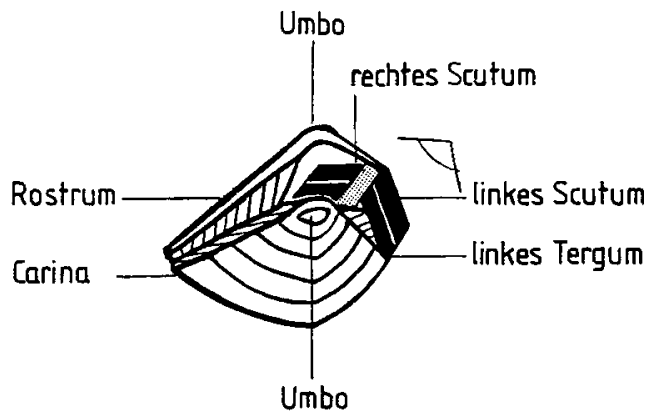

Abb. 47. Schema des asymmetrischen Gehäuses von Verruca stroemia. weiß = Rostrum und Carina; die Zuwachsstreifen umlaufen den apikal verschobenen Umbo (Schildbuckel) in Form exzentrischer Linien; schwarz = die zweiteiligen, annähernd senkrecht aufeinanderstehenden Opercularhälften; punktiert = der sich an der Gehäusewand öffnende Opercularspalt

zwei bedeutend kleinere Opercularplatten (Scutum und Tergum) ableiten. Die beiden letzteren stehen im Gegensatz zu den flach ansteigenden großen Mauerelementen steil aufgerichtet. Die beweglich gebliebene zweite Opercularhälfte knickt im rechten Winkel dazu ab und verschließt mit fest verbundenem Scutum und Tergum als einklappiger Deckel die Gehäuseöffnung. Der Deckelspalt öffnet sich am Gehäuserand parallel zu den unbeweglich in die Wand einbezogenen Opercularplatten (Abb. 47).

Die Larven sind zweiseitig symmetrisch gebaut. Die irreguläre Form des Gehäuses bildet sich während der Entwicklung der Skelettplatten nach der Metamorphose heraus, wobei der Zufall bestimmt, ob der rechten oder der linken Hälfte des Operculums die Aufgabe des beweglichen Deckels zufällt (Broch, 1924; Runnström, 1927).

Verruca stroemia (Abb. 48)

(a) Gehäuse niedrig, abgeflacht, Länge des basalen Durchmessers 4 bis $8 \mathrm{~mm}$, größer als die Höhe des Gehäuses, das Rostrum besitzt einen apikalen Umbo (Wirbel) mit parallel zur Basis verlaufenden Zuwachsstreifen und radial ausstrahlenden Falten. Letztere können fehlen. Zusammen mit dem Umbo der Carina erscheint das Gehäuse in Seitenansicht zweigipfelig. Die Verbindung beider Skelettplatten besteht aus randlich ineinandergreifenden Rippen, die sich zu mehr oder weniger großen radienähnlichen Flächen zusammenschließen, die Verbindungen sind jedoch nicht so stabil wie bei den Balaniden. Das unbeweglich in die Gehäusewand eingebaute Scutum - es ist größer als das Tergum - ragt mit einem spatelförmigen, der Adduktorkrista homologen Myophor (= mäuseohrartiger Fortsatz) in den Innenraum hinein. Zusammen mit der scutalen Randleiste des Tergums wird so eine basale Höhlung vom restlichen Innenraum abge- 


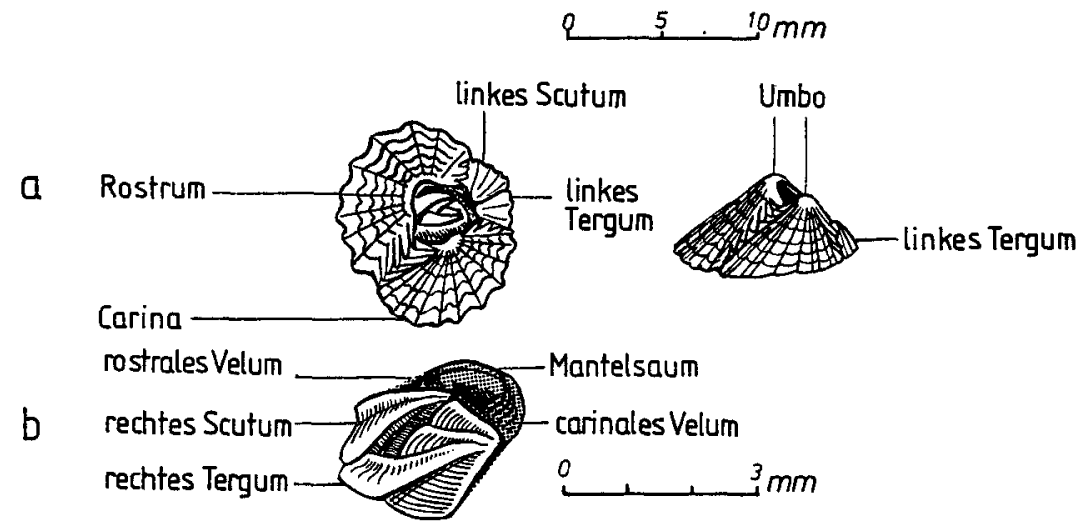

Abb. 48. Verruca stroemia. a Ansicht von oben und von der Seite; b Scutum und Tergum der beweglichen Deckelhälfte, im vorliegenden Fall, der rechten (nach Barnes \& Stone, 1973)

trennt. Auf der Außenseite stellen Randabschnitte, die den Radien und Alae der Balaniden entsprechen, die Verbindung zwischen Rostrum und Carina her. Die Grenzen zwischen den in die Mauerkrone einbezogenen Opercularplatten erscheinen dagegen als einfache Naht. Die Wandelemente sind einschichtig aufgebaut. Die beiden Platten der beweglichen Deckelhälften bilden eine Einheit, indem eine Leiste des Tergums in eine entsprechende Furche des Scutums einrastet (Broch, 1924). Der Mantelsaum ist zwischen den beweglichen und den unbeweglich in die Gehäusewand eingebauten Opercularelementen als ringförmiges Polster von weißlicher bis rötlicher Farbe ausgebildet. (b) Das Scutum der beweglichen Deckelhälfte ist stets kleiner als das Tergum, schmal und durch einen Kiel und einige schwach modellierte Rippen gekennzeichnet. Das trapezförmige Tergum besitzt eine stark hervortretende Diagonalleiste und zwei kürzere, kräftige Rippen, deren obere in die Furche unterhalb des scutalen Kiels eingreift. Auf der Innenseite sind beide Platten wenig strukturiert und schwach konkav gewölbt. Das Gewebe des Mantelsaums dehnt sich an beiden Enden des Spaltes, besonders auffällig am carinalen, velumartig auseinander, so daß ein weiter Raum für die austretenden Cirren entsteht (Stone \& Barnes, 1973). Da sich der Spalt seitlich an der Innenwand des Gehäuses öffnet, wird bei der Bewegung des Deckels der Eindruck hervorgerufen, ein Lid gleite rhythmisch über einem unregelmäßig geformten Augapfel auf und nieder. Die Basalplatte ist membranös.

\section{Beschreibung der Larven}

Als Planktonorganismen werden die Larven der Rankenfüßer im Laufe ihrer pelagischen Phase oft weiter verdriftet, als die Verbreitung der festsitzenden Adulten einer Art reicht. Wie bereits erwähnt, durchlaufen sie fünf Häutungen, denen sich nach einer sechsten das Cyprisstadium anschließt. Bei den verschiedenen Balanidenarten sind die Formen der einzelnen Stadien untereinander leicht zu verwechseln. Allein das sechste mit den voll entwickelten Komplexaugen und die Cypris heben sich durch Größe und äußere Merkmale deutlich von den jüngeren Larven ab. Daher erscheint in diesem Rahmen ein Hinweis auf die beiden letzten Phasen der Entwicklung ausreichend, der 
bei Bedarf über Literaturarbeiten erweitert werden kann (Barnes \& Costlow, 1961; Bassindale, 1936, 1964; Buchholz, 1951; Crisp, 1962; Daniel, 1958; Herz, 1933; Hoek, 1909; Jones \& Crisp, 1954; Knight-Jones \& Waugh 1949; Kühl, 1950; Pyefinch, 1948a, c; Le Reste, 1965; Runnström, 1925, 1927).

Die planktisch lebenden Larven sind - je nach Art - zu verschiedenen Jahreszeiten im Nordseewasser zu finden. Im Bereich wärmerer Wassertemperaturen erscheinen arktische Formen zeitiger, im Bereich kühlerer dagegen später im Jahr. Die Nauplien der Kaltwasserarten treten im Nordseeplankton im frühen Frühjahr, in arktischen Gewässern entsprechend später bis zum Ende des Sommers auf, jedoch stets zusammen mit der pflanzlichen Planktonblüte. Die Warmwasserarten entlassen dagegen ihre Larven erst in der wärmeren Jahreszeit ins Nordseewasser, wobei gleichfalls der Planktongehalt die Entwicklung bestimmt (Barnes, 1957; Barnes \& Stone, 1973; Moyse, 1963). Die Kaltwasserformen entwickeln meist nur eine Brut im Jahr mit relativ großen Larven, die Warmwasserformen dagegen mehrere, in kurzen Abständen aufeinanderfolgende Bruten mit kleineren Larven (Barnes, 1963; Crisp, 1957). Einige sublitorale Arten kühlerer Meere bilden eine Ausnahme, z. B. der schnell wachsende Balanus crenatus, dessen Frühjahrsbrut bereits im darauf folgenden Herbst geschlechtsreif wird, dann jedoch kleinere Nauplien erzeugt (Barnes, 1953). Ähnlich verhält sich Verruca stroemia (Barnes \& Stone, 1973). Aus diesen Beobachtungen läßt sich die Variationsbreite der Abmessungen erklären. Außerdem weist Pyefinch (1948b) darauf hin, daß auch durch die Lage des Fundorts Größenunterschiede bedingt sein können. So gibt Runnström (1925) die Länge der Cypris von Semibalanus balanoides aus dem Sammelgut bei Bergen, Norwegen, mit 1,2 mm an; Pyefinch (1948a) dagegen aus Sammelgut bei Millport, Irische See, mit 0,9-1,1 mm. Die Vermutung liegt nahe, daß sich in nordischen Gewässern die Wachstumsraten erhöhen. Die Meßergebnisse verschiedener Autoren sind in Tabelle 1 zusammengestellt.

Außer den Abmessungen können formale charakteristische Merkmale für die Bestimmung herangezogen werden wie: Umrißlinie des Carapaxes, Stellung der Seitenhörner und der Komplexaugen, Form des Labrums, Ausbildung und Größe des Caudalstachels im Verhältnis zum Abdominalfortsatz. Auch die Borstenzahl auf den GliedmaBen gilt als Bestimmungsmerkmal, worauf hier jedoch nicht näher eingegangen werden soll.

Semibalanus balanoides (Abb. 49a): Arktisch-boreal (Broch, 1924). Eine Brut jährlich. Die ersten Nauplien können bereits Ende Februar erscheinen, die ersten Cyprislarven Ende März, Besiedlungshöhepunkt Ende April bis Mitte Mai. (a) Länge des Nauplius VI 0,9-1,12 mm, Carapax seitlich gebaucht, Stirn stark gerundet, Hörner kurz und leicht caudalwärts gebogen, Labrum dreilappig. (b) Rückenlinie stark gerundet, Caudalstachel lang, schlank und gerade, deutlich länger als der ebenfalls schlanke Abdominalfortsatz. (c) Länge der Cypris 0,9-1,2 mm, Farbe gelb bis gelbbraun, hohe gewölbte Rückenlinie, in der Seitenansicht decken sich die beiden Komplexaugen mit dem Naupliusauge. Die Kalkreserven, die nach der Metamorphose zur Plattenentwicklung gebraucht werden, erscheinen während des Ansetzens in Form dunkler Granulae im Bereich des Vorder- und Hinterendes. Kleine Zeichnung: Hinterende breit gerundet.

Balanus balanus (Abb. 49a): Arktisch-boreal (Broch, 1924). Eine einzige Frühjahrsbrut mit Ausstoß- und Ansatzzeiten mehr oder weniger parallel zu denen von $S$. balanoides. (a) Länge des Nauplius VI 0,9-1,0 mm, Carapax nicht so umfangreich wie 


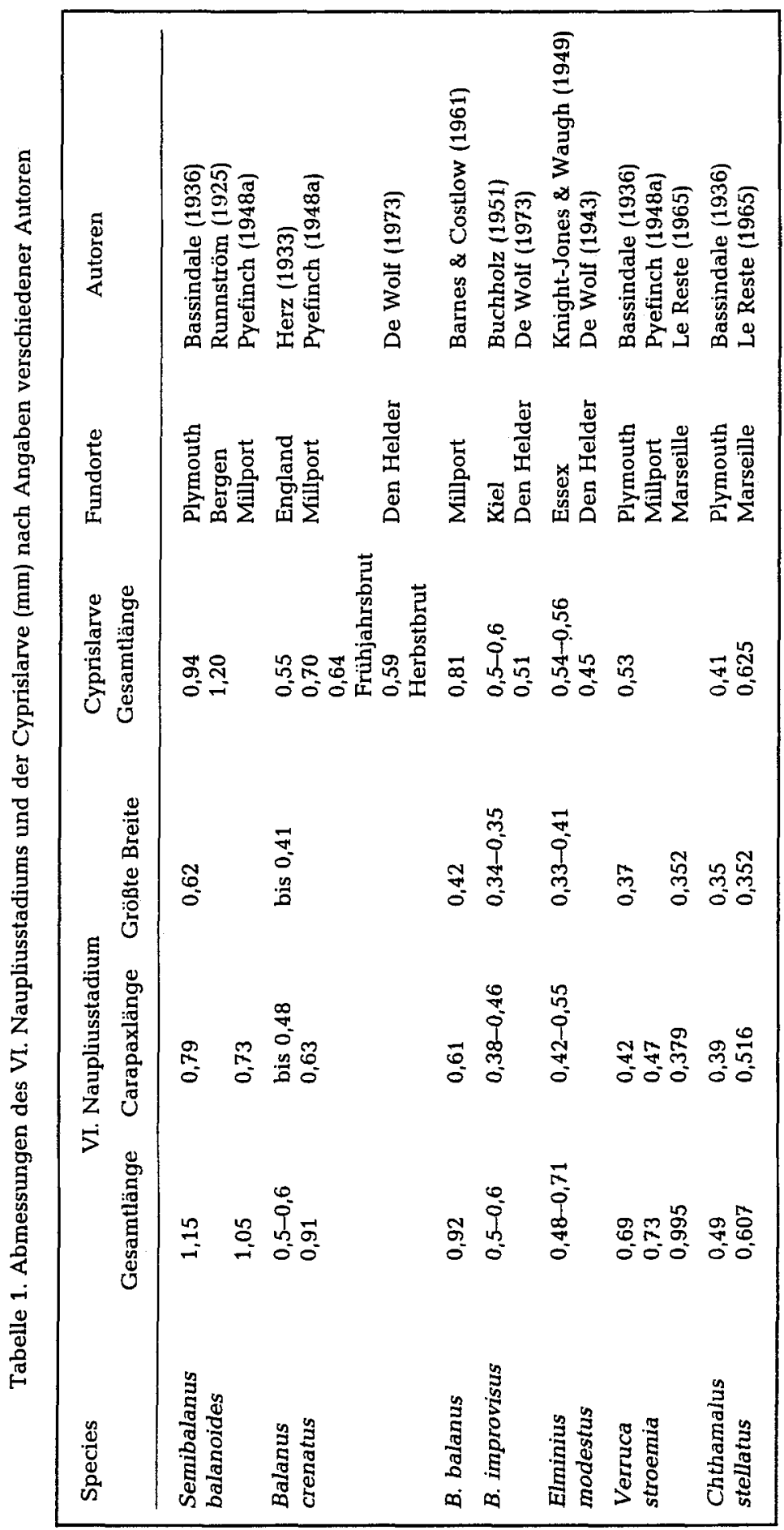




\section{ARKTISCH-BOREALE FORMEN}

\section{Semibalanus balanoides}

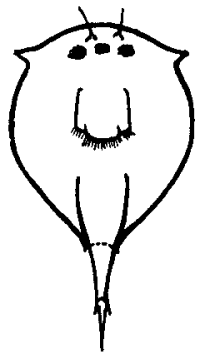

a

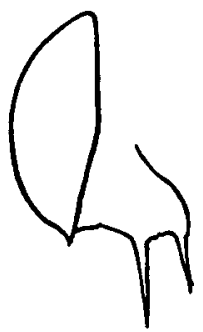

b

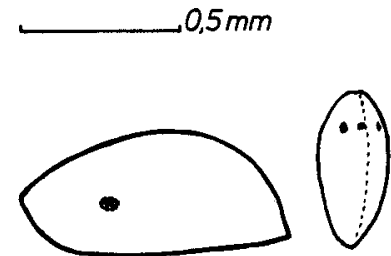

c

Balanus balanus

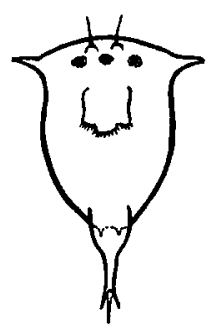

a

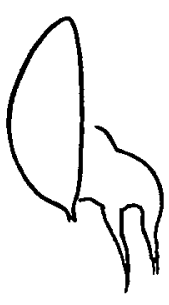

b

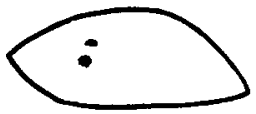

c

Balanus crenatus

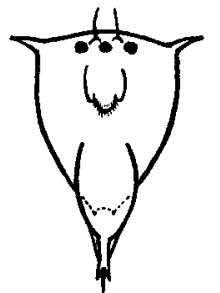

a

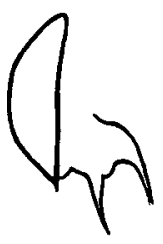

b

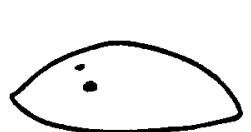<smiles>c1ccccc1</smiles>

c

Abb. 49a. Nauplius- und Cyprisstadien einiger Cirripedier. Arktisch-boreale Formen: Semibalanus balanoides (nach Pyefinch, 1948a); Balanus balanus (nach Barnes \& Costlow, 1961); B. crenatus (nach Pyefinch, 1948a) 


\section{ATLANTISCH-BOREALE-TROPISCHE FORMEN}

Balanus improvisus

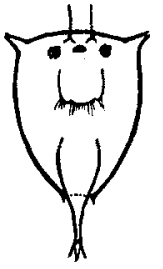

a

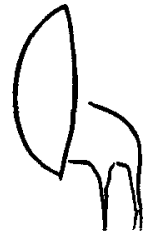

b

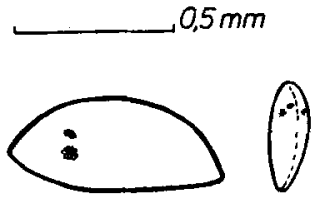

c

Elminius modestus

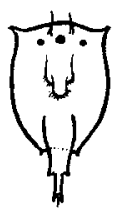

a

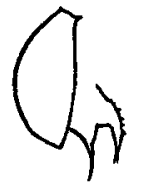

b

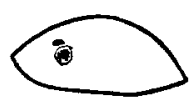

c

Verruca stroemia

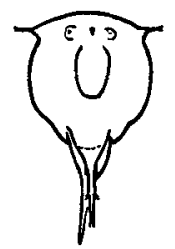

a

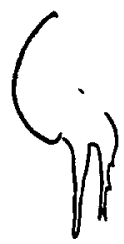

b

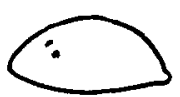

$c$

Chthamalus stellatus

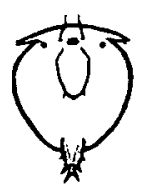

a

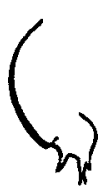

b

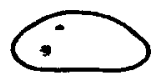

c

Abb. 49b. Nauplius- und Cyprisstadien, atlantisch-boreale bis tropische Formen: B. improvisus (nach Buchholz, 1951; Jones \& Crisp, 1954); Elminius modestus (nach Knight-Jones \& Waugh, 1949); Verruca stroemia (nach Bassindale, 1936, 1964); Chthamalus stellatus (nach Bassindale, 1936; Daniel, 1958); $a=$ Vertralansicht des VI. Naupliusstadiums (ohne Extremitäten); $b=$ Carapax und Caudalregion des VI. Naupliusstadiums in Seitenansicht; $c=$ Cyprislarve in Seitenansicht; kleine Zeichnung $=$ Dorsalansicht 
bei $S$. balanoides, gestreckter und weniger dreieckig als bei $B$. crenatus, jedoch seitlich deutlich gebaucht, Hörner ähnlich wie bei $B$. crenatus, Labrum dreilappig. (b) die Furca des Abdominalfortsatzes ist bedeutend längèr als bei $S$. balanoides, der Längenunterschied zum Caudalstachel geringer. (c) Länge der Cyrpis 0,81 mm, Farbe heller als bei $S$. balanoides, Form gestreckter und Rückenlinie flacher als bei $S$. balanoides

Balanus crenatus (Abb. 49a): Arktisch-boreal (Broch, 1924). Nauplien dieser Art sind vom Spätwinter bis zum Späthherbst im Plankton vertreten, am zahlreichsten jedoch während des Ausstoßes der Frühjahrsbrut. Erstes Besiedlungsmaximum im April/Mai, ein zweites, weitaus geringeres im September. (a) Länge des Nauplius VI 0,5-0,91 mm, Carapax elegant dreieckig, Stirn flacher als bei $S$. balanoides, Hörner seitlich ausgebreitet und länger als bei $S$. balanoides, Labrum dreilappig. (b) Rückenlinie flacher als bei $S$. balanoides, Caudalstachel gebogen, im Verhältnis zum Carapax relativ kurz, etwas länger als der Abdominalfortsatz. (c) Länge der Cypris 0,55-0,7 mm, Farbe weißlich bis glasklar, Rückenlinie flacher als bei $S$. balanoides mit einem leichten Knick an der höchsten Stelle, danach fällt die Profillinie mit gleichmäßiger Rundung zur Hinterkante ab, Augen relativ weit vom Stirnrand entfernt, die Komplexaugen decken sich nicht in Seitenansicht mit dem Naupliusauge; letzteres liegt dorsal verschoben. Kleine Zeichnung: Carapax schlank, Hinterende schlank zulaufend.

Balanus improvisus (Abb. 49b): Nach Southward (1957) ist B. improvisus eine tropische, an kühleres Klima angepaßte Art. Mehrere Bruten im Jahr von Mai bis zum Spätherbst. Beginn und Ende der Besiedlung bei $10^{\circ}$ Wassertemperatur, unter günstigen Bedingungen im Abstand von ca. 6 Wochen (Kühl, 1968). (a) Länge des Nauplius VI 0,5-0,6 mm, Carapax untersetzt, halb so breit wie lang, Stirn schwach gewölbt, Hörner seitlich abstehend, jedoch kürzer und mehr frontal gerichtet als bei $B$. crenatus, Labrum dreilappig. (b) Caudalstachel und Abdominalfortsatz laufen parallel und sind gleich lang. (c) Länge der Cypris 0,5-0,6 mm, Farbe dunkelgelb bis mattbraun, Form ähnlich der von $S$. balanoides, jedoch liegt das Naupliusauge dorsal verschoben und deckt sich in der Seitenansicht nicht mit den Komplexaugen. Die Kalkreserven für die spätere Plattenentwicklung werden während des sog. "Puppenstadiums" in Form geschlossener, dunkler Komplexe im Bereich des Vorder- und Hinterendes sichtbar, die sich im Lauf der Metamorphose zu kleineren Granulae verteilen (Kühl, 1967). Kleine Zeichnung: Hinterende stumpf.

Elminius modestus (Abb. 49b): Mehrere Bruten von Juni bis September (Kühl, 1954). Aussto $B$ der Larven bereits bei einer Wassertemperatur ab $6{ }^{\circ} \mathrm{C}$, bei gutem Nahrungsangebot im Abstand von 10 Tagen (Crisp \& Davies, 1955). (a) Länge des Nauplius VI 0,5-0,6 mm, Carapax nicht gedrungen, die Carapaxstacheln weit auseinanderstehend, sie werden in Ventralansicht nicht durch die Caudalregion verdeckt, Hörner kurz und leicht frontal gerichtet, Labrum schlank, dreilappig mit betontem Mittellappen. (b) Carapax gerundet, Hinterrand weit über das Abdomen vorspringend, Caudalstachel länger als Abdominalfortsatz. (c) Länge der Cypris 0,5-0,56, Farbe strohgelb bis glasklar, Rückenlinie flacher ansteigend und abfallend als bei $B$. improvisus, Hinterende spitzer.

Verruca stroemia (Abb. 49b): Nach Broch (1924) eine lusitanisch-atlantisch-boreale Form. Die Nauplien sind vom Frühwinter bis zum Spätherbst im Plankton zu finden, der Besiedlungshöhepunkt liegt jedoch im Frühjahr zur Zeit der Diatomeenblüte (Barnes \& Stone, 1973). Nach eigenen Beobachtungen setzten sich Jungtiere noch im September 
1971/72 an der Landungsbrücke Nordsylts an (Luther, 1976). (a) Länge des Nauplius VI $0,69-0,73 \mathrm{~mm}$, Carapax breit triangulär ohne die beiden Stacheln am Hinterrand, Hörner horizontal abstehend, länger als bei $S$. balanoides und Chthamalus stellatus, Labrum nicht dreilappig, schlank, am Hintergrund gerundet, Caudalregion fast so lang wie der Carapax, schlank und gerade (b) Caudalstachel länger als der Abdominalfortsatz. (c) Länge der Cypris 0,47-0,53, Profillinie des Rückens gleichmäßig, jedoch mit deutlich abgesetztem Hinterrand.

Chthamalus stellatus (Abb. 49b): Warmwasserart. Nach Funden von Powell (1954) scheint die nördlichste Verbreitung bei den Shetland-Inseln zu liegen, die östlichste im Kanal bei der Insel Wight. Funde bei Helgoland (Weltner, 1892) und im Kattegat im Jahre 1913 (Poulsen [1936] in Powell [1954]) wurden später nicht mehr bestätigt. Nach Crisp et al. (1981) handelt es sich in beiden Fällen offensichtlich um eine Verwechslung mit $S$. balanoides. Die Nauplien treten in britischen Gewässern während der wärmsten Monate auf; die Besiedlung erfolgt meist im September. (a) Länge des Nauplius VI 0,49 $\mathrm{mm}$, Carapax nicht triangulär sondern mehr rund geformt ohne Stacheln am Hinterrand, kurze etwas dorsal gerichtete Hörner, Komplexaugen meist nicht pigmentiert, Labrum einlappig mit je einem Zahn an beiden Seiten des Hinterrandes, Caudalregion sehr kurz, nur ein Fünftel der Carapaxlänge. (b) Caudalstachel wesentlich kürzer als der Abdominalfortsatz. (c) Länge der Cyprislarve 0,41-0,46 mm, Komplexaugen liegen im Verhältnis zum Naupliusauge frontalwärts verschoben.

\section{OKOLOGIE}

Die angegebenen Seepockenarten sind je nach Anpassung an physikalische Faktoren, Wahl des Substrates, dem Zeitpunkt der Reproduktion und der Überlebenschancen Feinden gegenüber in verschiedenen Wasserbereichen zu finden. Die oberhalb der Mitteltiden-Niedrigwasserlinie siedelnden Individuen erliegen häufig der Wirkung abiotischer Faktoren wie Temperatur- und Salzgehaltsschwankungen, Austrocknung, Wasserturbulenz oder Eisschliff, die darunter lebenden mehr biotischen Faktoren wie Feindeinwirkung oder Konkurrenz. Es gibt kaum scharf von einander abgegrenzte Besiedlungszonen und die Randgebiete, in denen mehrere Arten nebeneinander vorkommen, können sich in der Ausdehnung von Jahr zu Jahr, sogar je nach Jahreszeit verändern (Foster, 1971). Trotzdem gibt der Fundort schon manchen Hinweis, der die Bestimmung der Species erleichtern hilft.

\section{Zonierung}

Im oberen Gezeitenbereich, der überwiegend von abiotischen Faktoren bestimmt wird, siedeln Semibalanus balanoides, Elminius modestus und Chthamalus stellatus. Obwohl diese Arten auch in größeren Tiefen lebensfähig sind, unterliegen sie dort vielfach der Konkurrenz sublitoraler Formen.

Semibalanus balanoides ( $\mathrm{Abb} .50$ ) bevorzugt die lichtdurchflutete, gut durchlüftete Brandungszone. Das dickschalige Gehäuse schützt gegen Wasserturbulenz und Austrocknung - die Tiere können mehrere Stunden trockenliegen und nehmen dann den Luftsauerstoff mit Hilfe einer Mikropyle auf (Grainger \& Newell, 1965). Sie vertragen geringfügige Verschmutzung aus dem terrestrischen Bereich, besiedeln feste, tote 


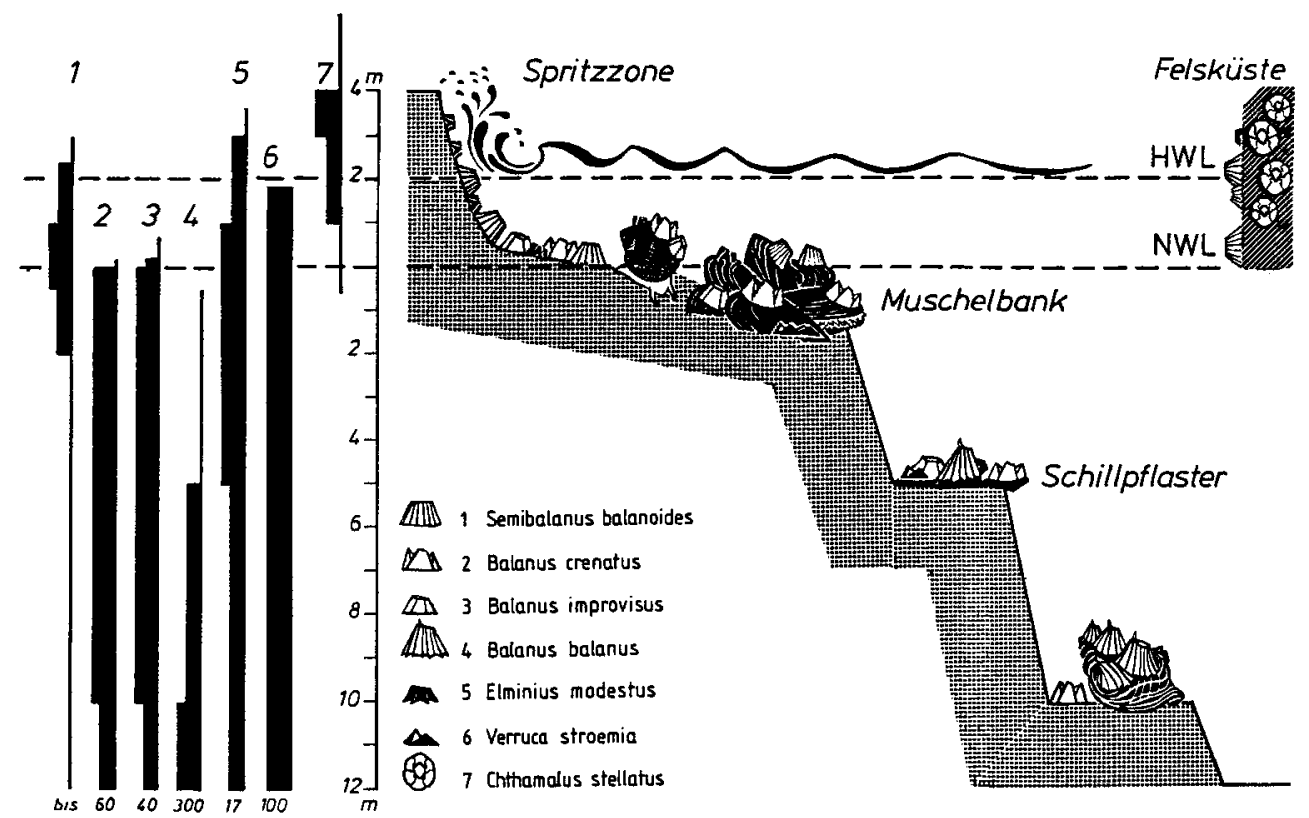

Abb. 50. Vertikale Verbreitung der Balanidenarten im deutschen Küstenraum. 1 = Semibalanus balanoides; $2=$ Balanus crenatus; $3=B$. improvisus; $4=B$. balanus; $5=$ Elminius modestus; $6=$ Verruca stroemia; $7=$ Chthamalus stellatus; HWL = Hochwasserlinie; NWL = Niedrigwasserlinie; breite Kolumne $=$ Besiedlung maximal; schmale Kolumne = Besiedlung mäßig; ausgezogene Linie = Besiedlung gering bis vereinzelt

Substrate, wobei sie treibendes Material und weichen Kreidekalk meiden (Moore \& Kitching, 1939). Sie sind auch auf organischem Kalk, wie den über die Wasserlinie tauchenden Muschelbänken zu finden, selbst auf der Strandschnecke Littorina littorea. Da selten Gehäuse der eignen Art besiedelt werden, entsteht kein Knäuelwachstum, um so häufiger die sog. Turm- und Buckelbildung. Alter durchschnittlich 3, im oberen Gezeitenbereich bis zu 5 Jahren. Geschlechtsreife im 2. Jahr. Als Voraussetzung für die Brutentwicklung gilt eine kritische Temperatur von $10-12^{\circ} \mathrm{C}$ (Crisp \& Patel, 1969; Ritz \& Crisp, 1970). Planktonfiltrierer mit Diatomeen als Hauptnahrung. Verbreitung überwiegend im Bereich zwischen Hoch- und Niedrigwasserlinie, weniger häufig darunter, bedingt durch die Konkurrenz anderer Arten.

Elminius modestus (Abb. 50) stammt aus der gemäßigten Zone der südlichen Hemisphäre (Foster, 1967), erstes Auftreten im Ärmelkanal 1944 (Crisp, 1958), wahrscheinlich mit Schiffsbewuchs eingeschleppt. Das relativ dünnschalige Gehäuse ist an wellenexponierten Standorten weniger widerstandsfähig als das von Semibalanus balanoides, jedoch besser gegen Austrocknung geschützt, da eine Kanalikulierung fehlt. Eine Mikropyle bildet sich ebenfalls. Da sich $E$. modestus wenig empfindlich gegen Verschmutzung aus dem terrestrischen Bereich zeigt, dringt er in trübe und ruhige Gewässer vor. Er erscheint weitgehend substrattolerant und besiedelt die eigenen Gehäuse gleich häufig wie die anderer Balanidenarten (Barnett et al., 1979). Alter ca. 1-11/2 Jahre, Geschlechtsreife bei guter Nahrungszufuhr bereits nach 8 Wochen (Crisp, 1958). Als Detritusfiltrierer nimmt er Partikel pflanzlicher und tierischer Herkunft auf. 
Verbreitung um die Mitteltiden-Niedrigwasserlinie, im Hochwasserbereich häufig noch über die obere Besiedlungsgrenze von $S$. balanoides hinaus. Unterhalb des Wasserspiegels ist er in $17 \mathrm{~m}$ Tiefe gefunden worden (Houghton \& Stubbings, 1963).

Chthamalus stellatus (Abb. 50) bevorzugt wie Semibalanus balanoides die lichtdurchflutete, gut durchlüftete Brandungszone, wo er sich in der Spritzzone weit oberhalb der Besiedlungsgrenze des letzteren ansetzen kann. Die einschichtigen Mauerplatten halten der Wellenergie besser stand als die kanalikulierten von $S$. balanoides und schützen den Tierkörper so erfolgreich gegen Austrocknen, daß er bis zu 14 Tagen ohne Wasserbedeckung überleben kann. Die Atmung findet dann gleichfalls über eine Mikropyle statt. Da er klares Wasser benötigt, ist er in Ästuaren, Häfen und Stillwasserbereichen weniger typisch, kann aber in geschützten Lagen bis $\mathrm{zu} 1 / 2 \mathrm{~m}$ unter der Wasserlinie gefunden werden (Klepal, 1971). Als Substrat dienen glatte Flächen der Steilküsten, in besonders exponierten Lagen Mulden und Rinnen im Gestein, daneben festliegende Blöcke ab mindestens $20 \mathrm{~cm}$ Durchmesser, die teilweise über die Wasserlinie hinausragen. Er setzt sich gelegentlich auf Gehäusen der eignen Art, Molluskenschalen und Tangen an. In dicht gepackten Kolonien bildet sich Turmwachstum aus. Alter bis zu 3 Jahren und mehr, Geschlechtsreife 9 bis 10 Monate nach der Metamorphose. Mehrere Bruten sind ab Mai möglich, doch scheinen in der Nordsee erst die im Juli/August ausgestoßenen Larven alle Stadien bis zum Ansetzen im Herbst durchlaufen zu können (Crisp, 1950). Kritische Temperatur zur Brutentwicklung 14 bis $15^{\circ} \mathrm{C}$ (Klepal \& Barnes, 1975). Planktonfresser mit Flagellaten als Hauptnahrung, wahrscheinlich der Hinweis auf die Herkunft aus tropischen Gewässern, da dort, wie in der Nordsee während der Sommermonate, Flagellaten die Zusammensetzung des Phytoplanktons bestimmen (Southward, 1976; Knight-Jones \& Moyse, 1961; Moyse \& Knight-Jones, 1967).

Im Gezeitenbereich um die Mitteltiden-Niedrigwasserlinie siedeln Arten wie Balanus crenatus und $B$. improvisus, die auf eine längere Wasserbedeckung angewiesen sind. Sie treten gleichfalls in großen Tiefen auf.

Balanus crenatus (Abb. 50) hat seine optimale Verbreitung unterhalb der Niedrigwasserlinie, ist jedoch noch in Tiefen bis zu $60 \mathrm{~m}$ mit $B$. balanus vergesellschaftet $\mathrm{zu}$ finden. Im Gegensatz zu Semibalanus balanoides kann er einen geringeren Sauerstoffgehalt des umgebenden Mediums vertragen. Das Fehlen der Mikropyle verhindert jedoch die Aufnahme des Luftsauerstoffs bei längerem Trockenliegen. Die obere Verbreitungsgrenze liegt bei höchstens $50 \mathrm{~cm}$ über der Niedrigwasserlinie. Da bei ständiger Wasserbedeckung die Nahrungsaufnahme nicht unterbrochen wird, wächst diese Art nicht nur schneller, sondern entwickelt sich auch früher zur Geschlechtsreife. Das Gehäuse erreicht vom Ansetzen im Frühjahr an bis zum Sommer einen basalen Durchmesser von 28 bis $30 \mathrm{~mm}$ (Pyefinch, 1948b). Die Geschlechtsreife tritt bereits bei einer Basisgröße von 12 bis $14 \mathrm{~mm}$ ein (Schütz, 1969). B. crenatus ist gegen Wasserturbulenz und Austrocknung weniger resistent als die eulitoralen Formen, verträgt einen geringeren Verschmutzungsgrad aus dem terrestrischen Bereich und bevorzugt vielfach den küstenfernen Siedlungsraum. Er besetzt jede Form von Hartböden, lebenden Substraten wie Mollusken, decapoden Krebsen und die Gehäuse aller Balanidenarten einschließlich der eigenen. Bei großer Siedlungsdichte entstehen Turm-, Buckel- und Knäuelformen. Alter 1 bis 2 Jahre, die kritische Temperatur für die Brutentwicklung liegt bei $17^{\circ} \mathrm{C}$ (Crisp \& Patel, 1969). Planktonfiltrierer. 
Balanus improvisus (Abb. 50) ist durch eine untere Verbreitungsgrenze bei $40 \mathrm{~m}$ Wassertiefe gekennzeichnet. Er reagiert empfindlicher auf Wasserturbulenz und Austrocknung, kann aber, obwohl ihm die Mikropyle fehlt, durch gute Wärmeverträglichkeit in geschützten Lagen, häufiger als $B$. crenatus, bis zu $60 \mathrm{~cm}$ oberhalb der Niedrigwasserlinie gefunden werden. Er verträgt als Detritusfiltrierer einen hohen Verschmutzungsgrad aus dem terrestrischen Bereich und dringt daher weit in Ästuaren, Kanäle und Hafengebiete ein. In der Substratwahl ist er ebenso tolerant wie $B$. crenatus und besiedelt Glas, Leder, Kunststoff, Algen und jede Art treibenden Materials, bewegliche tote und lebende Körper, auch den Kalk der eignen Art. Er produziert mehrere Bruten im Jahr. Der Ausstoß der Nauplien beginnt bei $10^{\circ} \mathrm{C}$ Wassertemperatur und endet, wenn diese im Herbst unter $10^{\circ} \mathrm{C}$ absinkt (Kühl, 1968). Geschlechtsreife bereits bei einem basalen Durchmesser von 6 bis $8 \mathrm{~mm}$ (Schütz, 1969). Alter 1 bis 21/2 Jahre (Subklew, 1969), Detritus- und Planktonfiltrierer.

Verruca stroemia (Abb. 50) und Balanus balanus gehören zu den .überwiegend im tiefen Wasser siedelnden Cirripedia-Arten. Sie können in geschützten Lagen vereinzelt bis dicht unter der Niedrigwasserlinie gefunden werden. Diese Form siedelt von der Niedrigwasserlinie an abwärts bis ca. $100 \mathrm{~m}$ Tiefe und bevorzugt schattige, geschützte Areale. Das Gehäuse ist empfindlich gegen Wasserturbulenz und Austrocknung, ebenso behindert ein höherer terrestrischer Verschmutzungsgrad den Entwicklungsgang (Barnes \& Stone, 1973). V. stroemia setzt sich an der Steilküste überwiegend in Mulden, unter Überhängen und Blöcken an, selten auf der glatten Gesteinsoberfläche. Sie kommt zusammen mit $B$, balanus auf Molluskenschalen vor, gelegentlich auch auf Krebspanzern, Laminarien und treibendem Holz. Die flachen Gehäuse können in dicht gepackten Gruppen eine Höhe erreichen, die dem basalen Durchmesser entspricht. Alter durchschnittlich wenig mehr als $1 \mathrm{Jahr}$, Geschlechtsreife bei einem basalen Durchmesser von $2 \mathrm{~mm}$. Das Brutverhalten ähnelt dem von B. crenatus: auf ein Frühjahrsmaximum, bestehend aus zwei Höhepunkten im Verlauf von ca. 6 Wochen, folgen Sommerbruten in unregelmäßigen Abständen bis zu einem geringen Herbstmaximum, nachdem die Jungtiere der Frühjahrsgeneration geschlechtsreif geworden sind. Die Brutentwicklung findet bei 6 bis $8^{\circ} \mathrm{C}$ statt (Barnes \& Barnes, 1975). V. stroemia filtriert Diatomeen und kleine organische Partikel, auch Formen des Zooplanktons, ist jedoch nicht auf die Diatomeenblüte des Frühjahrs angewiesen, obwohl diese die Entwicklung fördert (Stone \& Barnes, 1973).

Balanus balanus (Abb. 50), eine ausgesprochene Tiefenform, siedelt von wenig unterhalb der Niedrigwasserlinie an abwärts bis ca. $300 \mathrm{~m}$ Tiefe, bevorzugt strömungsund sauerstoffreiche Zonen mit ausgeglichenen Temperaturen, eine Reinwasserform. Sie ist auf Hartsubstrat zu finden, Schillböden, Muschel- und Schneckenschalen, gelegentlich auf dem Carapax größerer Krebse, seltener auf tief reichenden Muschelbänken oder als Ausnahmefall auf Material im Bereich der Niedrigwasserlinie, z. B. auf Holzleisten im Schutz eines Bohlenstegs im Nordsylter Wattenmeer (Luther, 1976). Das Aufeinandersiedeln mehrerer Generationen führt zu riffartigen Krustenbildungen, daneben ist Turmwuchs nicht ungewöhnlich. Alter bis zu 5 Jahren und mehr. Die Entwicklung der einzigen Brut pro Jahr mit besonders reichem Larvenausstoß ist von der Diatomeenblüte im Frühling abhängig. Die kritische Temperatur der Brutentwicklung liegt zwischen 10 und $14{ }^{\circ} \mathrm{C}$ (Crisp \& Patel, 1969), Diatomeen- und Detritusfiltrierer. 


\section{Temperatur und Salzgehalt}

Die vertikale wie auch die geographische Verbreitung ist neben anderen Faktoren von der Temperatur- (Southward, 1958, 1964a) und Salzgehaltstoleranz (Davenport, 1976) abhängig; z. B. überleben die Balaniden der oberen Gezeitenzone weitaus höhere Temperaturschwankungen als jene, die ständig vom Wasser bedeckt sind. Die Formen arktischer Gewässer sind kälteunempfindlicher, die der tropischen Gewässer wärmeverträglicher. Verruca stroemia, eine überwiegend boreale Art, kommt im nördlichen Mittelmeer einschließlich der Adria in Tiefen von 35 bis $50 \mathrm{~m}$ vor, da dort die Wassertemperaturen ausgeglichener sind (Kolosváry, 1941; Relini, 1969), in der Nordsee dagegen bis dicht unter der Niedrigwasserlinie. Balanus improvisus besiedelt die stark ausgesüßten Bereiche der Ostsee, während $B$. balanus dort nur in den Tiefen zu finden ist, wo sich das spezifisch schwerere Nordseewasser unter das leichtere Brackwasser geschoben hat, der eulitorale Semibalanus balanoides dagegen wanderte erst in die Kieler Bucht ein, als salzreiches Nordseewasser die dänische Küste entlang in südlicher Richtung vordrang (Schütz, 1969). Hinsichtlich des Salzgehalts teilt Davenport (1976) die Balaniden nach ihren natürlichen Standorten in drei Typen ein: (1) Seepocken der Küstengewässer und äußeren Flußmündungen; sie sind mehr oder weniger euryhalin mit einem Aktivitätsoptimum um $30 \% \mathrm{~S}$ und gelten nach Foster (1970) als gute Osmokonformer, die sich an niedrige Salzgehalte adaptieren lassen. (2) Brackwasserformen: sie sind extrem euryhalin und vertragen Verdünnungen bis zu $3 \% \mathrm{~S}$ (Aktivitätsoptimum zwischen 6 und 30\%o). (3) Sublitorale Arten mit mehr oder weniger stenohalinem Charakter (Aktivitätsoptimum zwischen 30 und $40 \%$ S).

Semibalanus balanoides ist begrenzt eurytherm (Abb. 51) mit jahreszeitlich bedingter Temperaturanpassung (Crisp \& Ritz, 1967) und euryhalin (Tab. 2). Er kann, bedingt durch Niederschläge während des Trock্enliegens, Süßwasserüberspülung bis zu $48 \mathrm{~h}$ überleben (Visscher, 1928). Verbreitung überwiegend in arktischen und subarktischen Gewässern, kosmopolitisch. Er siedelt entlang der skandinavischen Küste bis Arcachon an der französischen Atlantikküste (Barnes, 1958) und ist stellenweise auch an der nordwestspanischen Küste nachgewiesen worden (Fischer-Piette \& Prenant, 1956). Außerhalb Europas kommt er entlang der Beringstraße bis Japen und an der westlichen Atlantikküste von Grönland bis Nord-Carolina vor (Barnes \& Healy, 1965).

Balanus crenatus ist stenotherm mit euryhalinem Charakter (Abb. 51), jedoch ohne jahreszeitliche Anpassung. Er scheint etwas euryhaliner als S. balanoides zu sein (Tab. 2); seine Besiedlungsgrenze in der Ostsee ist bei $10 \%$ S erreicht (Schütz, 1969). Zirkumpolar, südliche Verbreitung in Europa entlang der französischen Atlantikküste bis zur Gironde-Mündung (Lewis, 1964), an der amerikanischen Atlantikküste bis New Jersey. und an der Pazifikküste bis Neukalifornien (Crisp \& Patel, 1969).

Balanus balanus ist begrenzt eurytherm (Abb. 51) und als Form des Sublitorals stenohalin (Tab. 2). In der Ostsee reicht seine Verbreitung bis zu einem Salzgehalt von 25-27 \% (Schütz, 1969). Zirkumpolar (nach Brock, 1924) auch bipolar. Vorkommen in arktischen Gewässern, beginnend bei Spitzbergen über Grönland, Labrador, entlang der westlichen Küste Alaskas bis zur Beringsee und dem Ochotskischen Meer. Südliche Begrenzung in der Deutschen Bucht und der Westküste Irlands, an der amerikanischen Küste bis Long Island (Bassindale, 1964).

Balanus improvisus ist eurytherm, jedoch frostempfindlich (Abb. 51). Seine nördli- 


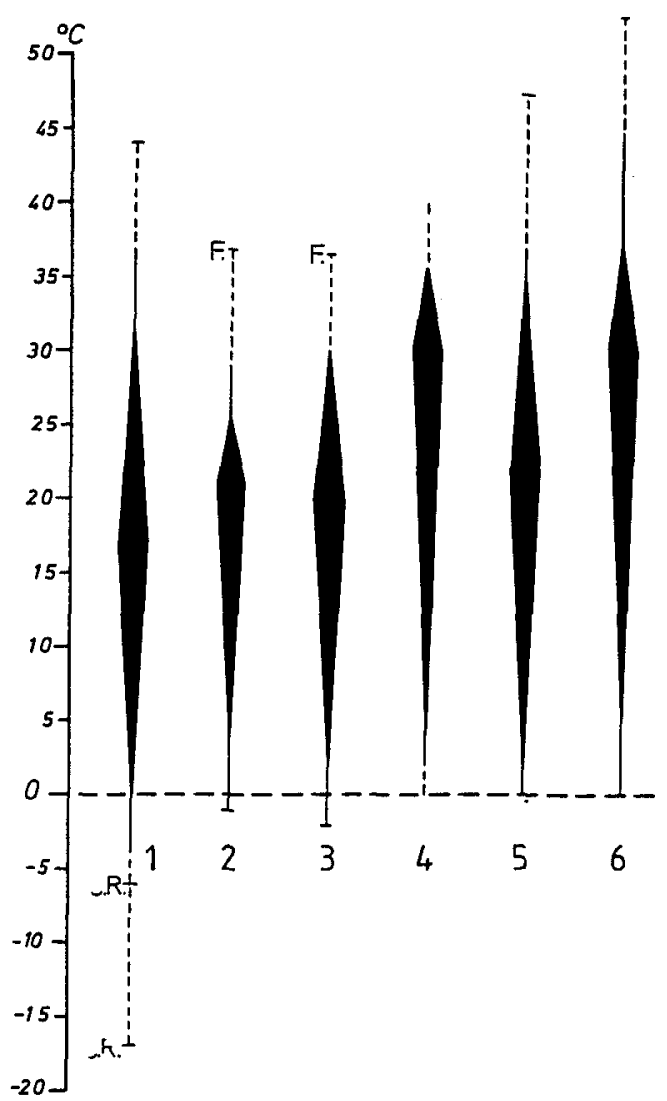

Abb. 51. Temperaturabhängigkeit einiger Balanidenarten, bezogen auf die Cirrenaktivität, nach Laborversuchen von Southward $(1955,1957,1958)$; andere Autoren: Crisp \& Ritz (1967) $=$ C. R., Foster (1969) = F. 1 = Semibalanus balanoides; $2=$ Balanus crenatus; $3=B$. balanus; $4=B$. improvisus; $5=$ Elminius modestus; $6=$ Chthamalus stellatus; größte Breite der Kolumne = Optimum der Aktivität, von da an Abnahme bis zum Stillstand; ausgezogene Linie = Bereich ohne Aktivität bis zum Hitze- bzw. Kältetod; gestrichelte Linie = Letalbereich; bei 4 Letalbereich unbekannt

che Verbreitung reicht nicht über den Oslofjord hinaus (Broch, 1924). Southward (1957) hält ihn für eine an kaltes Klima angepaßte tropische Art. Er gilt als extrem euryhalin und gedeiht in normalem Seewasser ebenso gut wie in einem stark ausgesüßten Medium (Tab. 2). Nauplien können noch bei einem Salzgehalt von $6 \%$ entwickelt werden (Schütz, 1969). Kosmopolitisch, Verbreitung entlang der Atlantikküsten. Außerdem ist er aus den indisch-pazifischen und australischen Gewässern bekannt.

Elminius modestus gilt als extrem eurytherm, ist jedoch frostempfindlich (Abb. 51). Nachdem er während des 2. Weltkrieges in den Kanal eingeschleppt wurde, wies ihn Kühl (1954) erstmals im Elbe-Ästuar nach. Von dort her breitete er sich in die Deutsche Bucht aus (Kühl, 1963). In den flachen Wattgebieten wird eine all zu starke Vermehrung durch Ausfrieren im Winter eingedämmt (Kühl, 1967). Southward (1962) bezeichnet ihn als Bindeglied zwischen tropischen und atlantischen Verbreitungsformen. Er ist wie $S$. 
Tabelle 2. Salzgehaltsresistenz einiger Balanidenarten bei $10^{\circ} \mathrm{C}$ Wassertemperatur nach Foster (1970)

\begin{tabular}{|c|c|c|c|c|}
\hline Species & $\begin{array}{c}\text { Standorttypen } \\
\text { nach Davenport } \\
(1976)\end{array}$ & $\begin{array}{l}\text { Aktivitäts- } \\
\text { Optimum (\%o) }\end{array}$ & $\begin{array}{c}\text { Untere } \\
\text { Aktivitäts- } \\
\text { grenze (\%o) }\end{array}$ & $\begin{array}{c}\text { Obere } \\
\text { Aktivitäts- } \\
\text { grenze (\%o) }\end{array}$ \\
\hline $\begin{array}{l}\text { Semibalanus } \\
\text { balanoides }\end{array}$ & \multirow{4}{*}{$\begin{array}{l}\text { Küsten- } \\
\text { gewässer - } \\
\text { äußere } \\
\text { Bereiche } \\
\text { von } \\
\text { Asstuarien }\end{array}$} & 30 & $12-14$ & $50-55$ \\
\hline $\begin{array}{l}\text { Elminius } \\
\text { modestus }\end{array}$ & & 30 & $\begin{array}{l}14 \\
10^{* *}\end{array}$ & $>55$ \\
\hline $\begin{array}{l}\text { Balanus } \\
\text { crenatus }\end{array}$ & & 30 & $12-14$ & $50-55$ \\
\hline $\begin{array}{l}\text { Chthamalus } \\
\text { stellatus }\end{array}$ & & 30 & 20 & \\
\hline B. improvisus & Brackwasser & $6-30^{*}$ & 3 & \\
\hline B. balanus & Sublitoral & $30-40^{* *}$ & & \\
\hline
\end{tabular}

balanoides euryhalin dringt jedoch tiefer in Ästuaren ein. Ursprungsgebiet sind australische und neuseeländische Gewässer, später nach Süd-Afrika und Europa eingeschleppt (Barnes et al., 1972; Crisp, 1958; Fischer-Piette \& Prenant, 1956).

Chthamalus stellatus ist als Warmwasserform extrem eurytherm (Abb. 51). Davenport (1976) rechnet ihn zu den stenohalinen Arten (Tab. 2), obwohl er als Besiedler des Supralitorals häufig Niederschlägen ausgesetzt ist und Süßwasserüberspülungen bis zu 48, sogar $60 \mathrm{~h}$ standzuhalten vermag (Visscher, 1928). Verbreitung von der tropischen Zone West-Afrikas bei Cap Verde (Southward, 1976) bis zu den Shetland-Inseln an der schottischen Küste (Southward, 1964b). Die östliche Grenze befindet sich im Kanal bei der Insel Wight, im lusitanischen Raum reicht diese bis zum Schwarzen Meer (Carli, 1966).

Verruca stroemia unterscheidet sich in der Art der Cirrenbewegung wesentlich von den Balanomorphen, sie entspricht mehr der der Lepatiden (Stone \& Barnes, 1973). Es ist daher angebracht, die Ergebnisse von Barnes \& Barnes (1975) sowie von Barnes \& Klepal, (1974) hinsichtlich der Temperaturtoleranz nicht in Abbildung 51 einzubauen. Experimentelle Untersuchungen haben gezeigt, daß $5^{\circ} \mathrm{C}$ als optimaler Temperaturbereich einzustufen ist; der kritische Temperaturbereich liegt zwischen 15 und $20^{\circ} \mathrm{C}$. Bei $20^{\circ} \mathrm{C}$ hörte die Cirrentätigkeit auf. $V$. stroemia steht zwischen den küstenbewohnenden und sublitoralen Formen. Broch (1924) bezeichnet diese Art als euryhalin, da sie noch im Oslofjord gefunden wird. Nach Barnes \& Klepal (1974) bleibt sie zwischen 15 und $40 \% \mathrm{~S}$ voll aktiv, der untere Letalbereich befindet sich bei 3 bis $5 \% \mathrm{~S}$. Die Verbreitung reicht von Spitzbergen entlang der östlichen Atlantikküste bis ins nördliche Mittelmeer. Die Art fehlt in der Ostsee und an der amerikanischen Atlantikküste. 


\section{Konkurrenten und Räuber}

Die mögliche Verbreitung, die durch Temperatur- und Salzgehaltsanpassungen gegeben ist, wird oft weit mehr durch biotische Faktoren bestimmt wie: Zeitpunkt und Zahl der Bruten, Siedlungsdauer, Nahrungsangebot, Räuber- und Beute-Verhältnis, Befall durch Parasiten oder zwischenartliche Konkurrenzen (Newell, 1970). Eine frühzeitige Larvenentwicklung begünstigt in der Nordsee arktische Arten vor den Warmwasserformen, die erst später bei höheren Temperaturen ihre Nauplien ausstoßen. Werden dagegen die Frühjahrspopulationen durch Einflüsse biotischer oder abiotischer Natur dezimiert, können die zahlreichen Bruten der Warmwasserarten in den frei gewordenen Raum nachrücken und ihn, falls sie den Winter überdauern, für eine Neubesiedlung der Kaltwasserformen blockieren.

Als klassisches Beispiel für zwischenartliche Konkurrenzen beschrieb Connell (1961b), Southward (1967) und Southward \& Crisp (1956) die Veränderlichkeit der Populationsgrenzen zwischen Semibalanus balanoides und Chthamalus stellatus. Im Sublitoral verdrängt Balanus crenatus durch sein schnelleres Wachstum nach der Metamorphose den sich langsamer entwickelnden $S$. balanoides in der Gezeitenzone (Meadows, 1969), in der Ostsee den auf demselben Niveau lebenden, jedoch später siedelnden $B$. improvisus in den Bereich der Niedrigwasserlinie zurück (Schütz, 1969), wo letzterer durch seine bessere Trockenresistenz überleben kann (Abel \& Subclew, 1960). Elminius modestus erweist sich durch Anpassung an höhere Temperaturen und durch seine Fruchtbarkeit als Konkurrent für die einheimischen Arten (Barnett \& Crisp, 1979), vor allem im Bereich der Ästuarien (Barnes \& Klepal 1974; Crisp, 1958; Foster, 1970). In frostgefährdeten Flachwassergebieten, wie der Gezeitenzone des Wattenmeeres, ist dagegen sein Vordringen begrenzt (Kühl, 1967). Junge Miesmuscheln treten als Nahrungskonkurrenten auf und überwachsen die Seepockenkolonien (Kühl, 1951; Paine, 1974). Räuber reißen je nach Siedlungsbereich Lücken in das Populationsmuster (Abb. 52), wobei ausgesprochen räuberische Formen, wie die Purpurschnecke, ihre Beute gezielt (Connell, 1961a), Weider dagegen, wie Strandschnecken, mehr oder weniger zufällig aufnehmen (Krüger, 1940). Andere Feinde werden den Balaniden über eine nur relativ kurze Zeitspanne gefährlich. Z. B. dezimieren eben metamorphosierte Seesterne die Frühjahrspopulation im Sublitoral, um sich mit zunehmendem Wachstum einem größeren Beutetier zuzuwenden (Luther, 1976). Auch Vögel, wie der Steinwälzer (Arenaria interpres) vertilgen Seepocken (Bassindale, 1964). Parasiten, wie der Isopode Hemioniscus balani (Southward \& Crisp, 1954) und die Gregarine Cephaloidophora communis (Moore, 1935) können die infizierten Balaniden nicht nur in ihrer Entwicklung hemmen, sondern auch ihre Sterilisation herbeiführen. Viele Planktonfiltrierer ernähren sich von Naupliuslarven und nur die große Fruchtbarkeit der Seepocken kann der Verlustziffer entgegenwirken. Ergebnisse der Felduntersuchungen über Populationsstrukturen hat Connell (1975) zusammengetragen.

\section{IRRGÄSTE}

Außer den bisher aufgeführten Formen nicht parasitischer Rankenfüßer treten gelegentlich Irrläufer in den deutschen Küstengewässern auf, die durch die atlantische Drift in die Nordsee gelangt sind. Im Juli/August finden sich fast regelmäßig Entenmuscheln als Treibgut im Spülsaum, und zwar Lepas anatifera und L. fascicularis. Die 


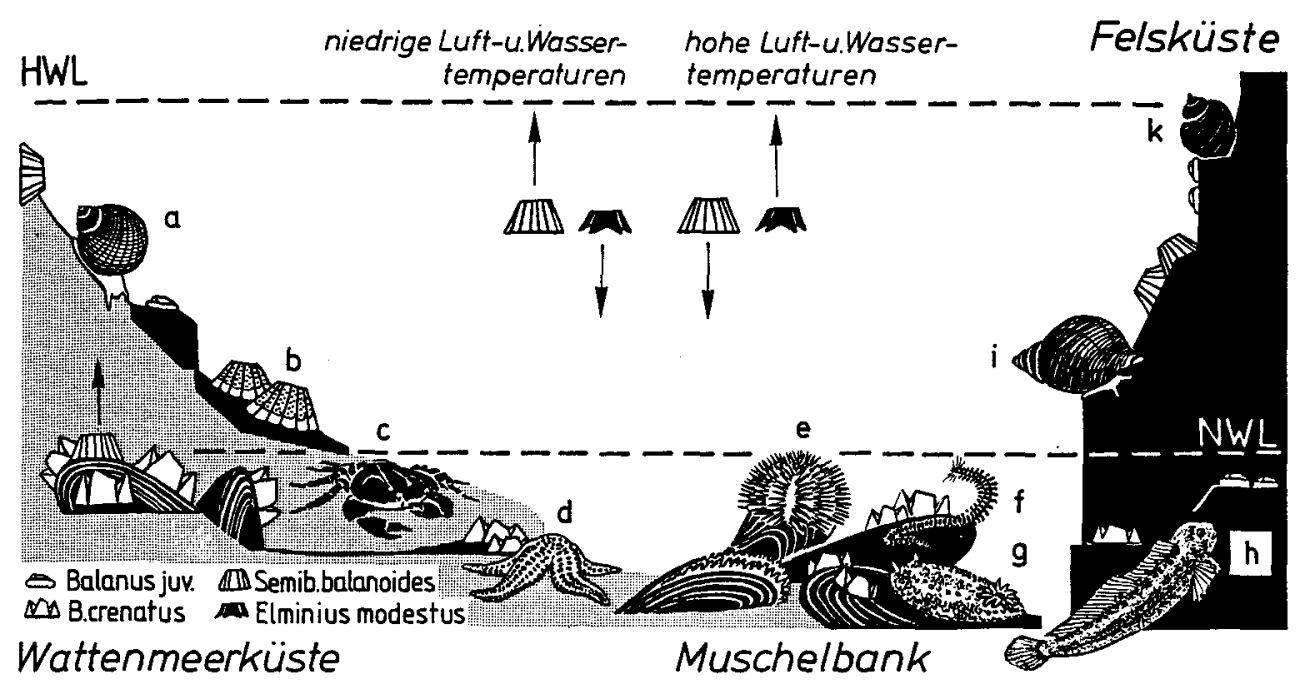

Abb. 52. Veränderung des Siedlungsmusters durch zwischenartliche Konkurrenzen und durch Räuber. a = Strandschnecke (Littorina littorea), junge Balaniden abweidend (Krüger, 1940); $b=$ Seepocken, von kalkbohrenden Algen (Gomontia polyrhiza) befallen; sie sind erhöht erosionsgefährdet (Parke \& Moore, 1935; Schäfer, 1938); $c=$ räuberische junge Strandkrabbe (Carcinus maenas); $\mathrm{d}=$ junger Seestern (Asterias rubens) in Freßstellung (Hancock, 1955); e = räuberischer Strandseeigel (Psammechinus miliaris) (Hancock, 1957); $\mathrm{f}=$ räuberischer Polychaet (Eulalia viridis) (Moore \& Kitching, 1939), wird von Emson (1977) jedoch eher als Vertilger abgestorbener Exemplare angesehen; $\mathrm{g}=$ räuberische Nacktschnecke (Onchidoris bilammelata, Syn. fusca) (Barnes \& Powell, 1954); $\mathrm{h}=$ ein Schleimfisch (Blennius pholis), junge Seepocken abpickend (Moore, 1935); i = bohrende Purpurschnecke (Nucella lapillus) (Connell, 1961a); $\mathrm{k}=$ weidende Felsenstrandschnecke (Littorina saxatilis) (Bassindale, 1964; Krüger, 1940); Pfeil = Richtung der Ausweitung, bzw. des Rückzugs einer Population in Relation zu Luft- und Wassertemperaturen (Connell, 1961b); HWL = Hochwasserlinie; NWL = Niedrigwasserlinie

Lepadomorpha umfassen mehr als 320 Arten. Zur Familie der Lepatidae gehören viele Kosmopoliten wie die beiden genannten. Ihre Fortpflanzungsgebiete liegen in den ozeanischen Bereichen der Tropen und Subtropen.

Im Typus der Entenmuscheln ist auf andere Weise der sessile Habitus verwirklicht. Der Vorderkopf bildet keine Haftscheibe sondern einen stielartigen, biegsamen Pedunculus. Von pedunculaten Formen lassen sich einerseits, unabhängig von einander, die Reihe der Verrucomorpha, andererseits die der hochentwickelten Balanomorpha ableiten (Krüger, 1940). Ein Längenwachstum des Vorderkopfs kann noch bei den Balaniden beobachtet werden, deren Gehäuse die sog. Turm- oder Tulpenform angenommen haben (Abb. 53). Der zusammen mit dem Rumpf rechtwinkelig abgeknickte Hinterkopf, vorwiegend als Capitulum bezeichnet, ist von mehreren Kalkschildern geschützt. Sie bilden im Gegensatz zu den Balaniden ein deutlich zweiseitig symmetrisches Gehäuse, worauf sich der Name: Enten-"Muschel" bezieht. Die Skelettelemente besitzen, wie auch bei den Verrucomorpha, eine schildförmige Erhebung, den Umbo, um den mehr oder weniger deutlich Wachstumsstreifen angelagert sind.

Lepas anatifera (Abb. 54, links): Der unbeschuppte, purpurbraune Stiel erreicht eine Ausdehnung bis zu $80 \mathrm{~cm}$. Das deutlich abgesetzte Capitulum wird ca. $5 \mathrm{~cm}$ lang. Die 
bläulich-weißen Schilder, zwischen denen die dunkle Mantelkutikula in unterschiedlicher Breite hervortritt, sind glatt. Die schmal elliptische Carina sitzt dem Mantel dorsal wie ein Schiffskiel auf und ist mit einer gabeligen Basalpartie an der Grenze zum Stiel in die Haut eingebettet. Zu beiden Seiten der Carina schließen sich je ein Paar großer, dreieckiger Scuta und ein Paar kleinere Terga an. Das rechte Scutum trägt einen mehr oder weniger gut entwickelten Zahn, der sich am Stielende, kurz unter der Offnung des Mantelspaltes, in die Haut einsenkt. Aus dem ventral liegenden Mantelspalt treten 6 Paar stark beborsteter Cirren als Fangapparat heraus. Die Nahrung besteht hauptsächlich aus tierischem Plankton, wie Nauplien und Copepoden. Als Substrat dient driftendes Material (Holz, Flaschen und Algen). Boëtius (1952) beobachtete Jungtiere, die sich sogar an festsitzenden Algen angesiedelt haben mußten. Auch an Schiffsrümpfen und Bojen sind Entenmuscheln regelmäßig zu finden.

Das Fortpflanzungsgebiet von $L$. anatifera liegt im atlantischen Bereich des Golfstroms bei einer Wassertemperatur von mindestens 18 bis $20^{\circ} \mathrm{C}$ (Patel, 1959). Nach Broch (1924) befindet sich die Grenze, wo sich Larven noch an ein Substrat ansetzen können, im Golfstromwasser nahe der Färöer- und Shetland-Inseln. Ausgewachsene Individuen dagegen driften die westliche und nördliche Küste Norwegens entlang. Er bezeichnet $L$. anatifera als eurytherm jedoch mit stenohalinem Charakter, da diese Art nur selten den Skagerrak als Grenze zur Ostsee erreicht.

Lepas fascicularis (Abb. 54, rechts): Der nackte, bläulich-weiße bis gelbliche Stiel bleibt kürzer als das Capitulum. Die Kalkschilder sind glatt und leicht durchscheinend. Der Umriß des Gehäuses ergibt ein unregelmäßiges Viereck von ungefähr $4 \mathrm{~cm}$ Länge. Die schiffskielartige Carina ist apikal zugespitzt und knickt stielwärts plattenförmig ab. Beide Scuta besitzen einen stielwärts weisenden Zahn. Ihre basalen Ränder sind nach außen umgebogen, so daß das Capitulum wie ein Helm dem Pedunculus aufsitzt. Die Cyprislarven heften sich an zum Teil winzigen treibenden Körpern an (Algenreste,
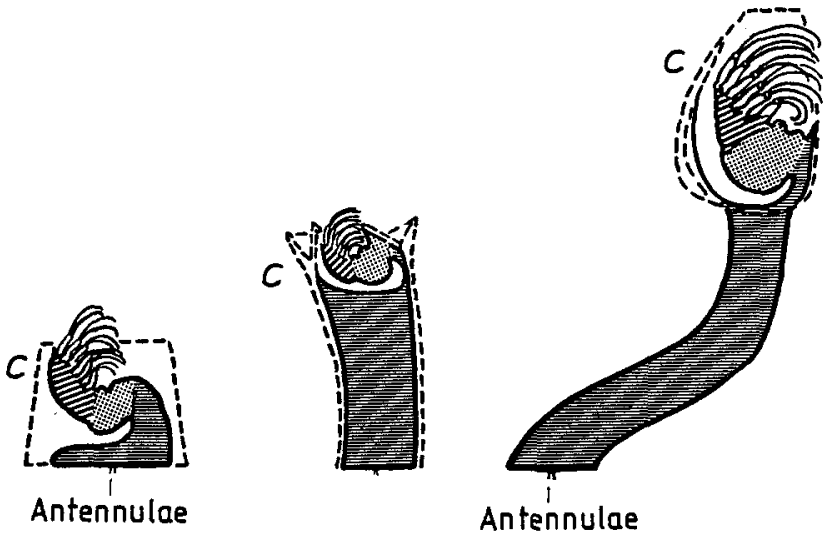

Abb. 53. Orientierung der Körperabschnitte bei Seepocken und Entenmuscheln. Links Balanus sp. mit scheibenartigem Vorderkopf, Patellawuchs. Mitte Balanus crenatus aus einer dicht gedrängten Siedlung mit verlängertem Vorderkopf, Gehäuse turmförmig (nach Gutmann, 1960). Rechts Lepas anatifera mit zum biegsamen Stiel verlängertem Vorderkopf. $c=$ carinal gelegene Seite der Gehäuse; gestrichelte Linie = Umriß der Gehäuse; waagerecht schraffiert $=$ Vorderkopf $;$ punktiert $=$ Hinterkopf; schräg schraffiert $=$ Thorax 


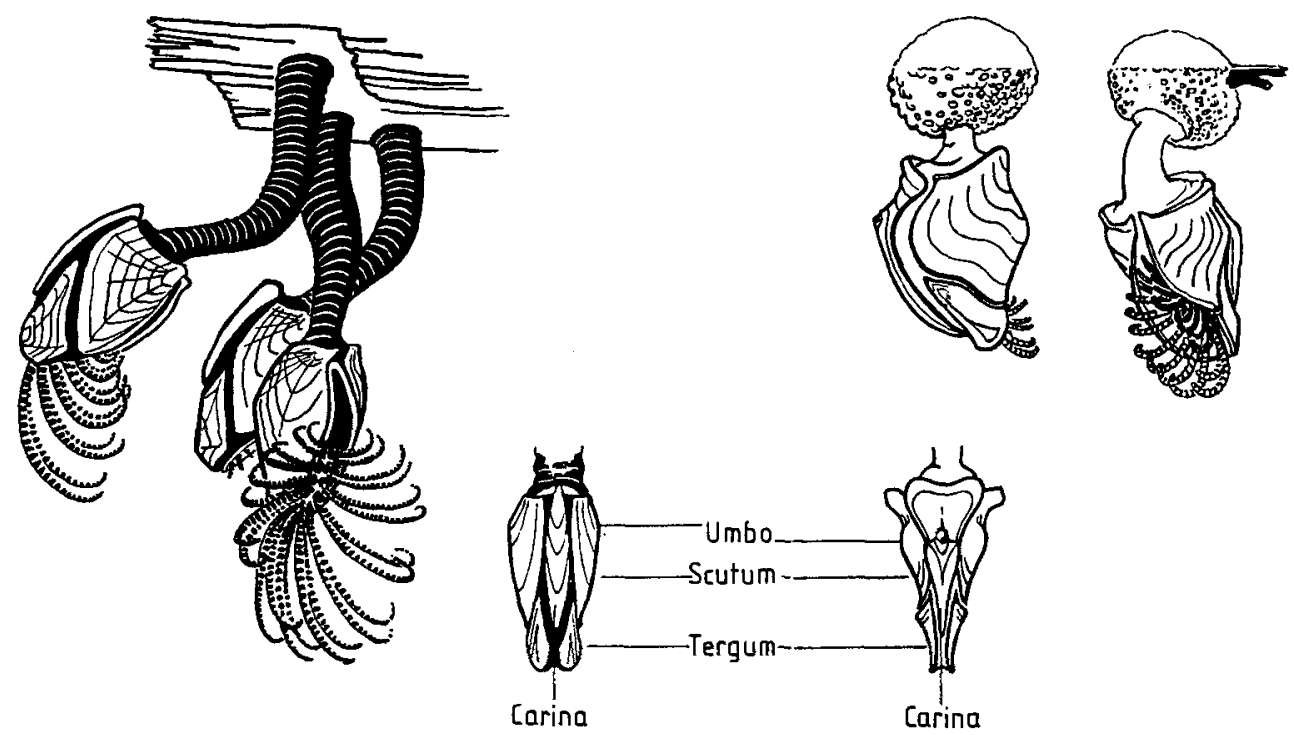

Abb. 54. Entenmuscheln als "Treibgut" in der Nordsee. Links oben Lepas anatifera, an Treibholz angeheftet, Seitenansicht und Ansicht mit geöffnetem Mantelspalt. Links unten Dorsalansicht mit der schmalen, kielartigen Carina. Rechts oben Lepas fascicularis. mit Hilfe des Schaumfloßes schwimmend, Seitenansicht und Ansicht mit geöffnetem Mantelspalt. Rechts unten Dorsalansicht mit der kielartigen, rostral verbreiterten Carina

Holz- und Korkbruchstücke, Vogelfedern). Darwin beschreibt als Substrat tote Exemplare der Staatenqualle Velella sp., Gehäuse der Tintenschnecke Spirula sp. und der pelagisch lebenden Schnecke Janthina sp., alles ausschließlich Formen tropischer Meere. Bevor mit dem Heranwachsen der Jungtiere das Substrat seine Tragfähigkeit verliert, scheidet die Zementdrüse, die zum Anheften der Cyprislarve dient, an Stelle des Klebstoffes ein anders geartetes Sekret ab, das in konzentrischen Schichten ein mit Gasblasen erfülltes, kugeliges Schaumfloß aufbaut. Der ursprüngliche Ansatzkörper kann herausragen oder bleibt wegen seiner Kleinheit im Inneren verborgen.

Die von Darwin beschriebenen Substrate belegen Lepas fascicularis als Hochseeform tropischer und subtropischer Meere, wo sie in ausgedehnten Schwärmen an der Oberfläche treibt. Durch Wind und Wasser verdriftet, gelangen Teile der Schwärme bei entsprechender Wetterlage bis in die Nähe der Nordsee. Der warme Golfstrom begünstigt die Eireifung und die ausgestoßenen Larven heften sich an Treibkörpern der umgebenden nordwesteuropäischen Meeresgebiete an, z. B. Fucus vesiculosus (Thörner \& Ankel, 1966). So können unter besonders günstigen Bedingungen Sekundärschwärme entstehen und in die Nordsee verdriftet werden. Auf solche Sekundärschwärme ist in manchen Jahren das starke Auftreten von $L$. fascicularis zurückzuführen, die sonst in nur geringer Zahl das sommerliche Plankton bereichert. Die niedrigen Wassertemperaturen der Nordsee lassen die Drift an der Westküste Norwegens enden und verhindern jegliche Eireifung. Broch (1924) bezeichnet die Art als stenotherm, im Gegensatz zu Lepas anatifera jedoch als euryhalin, da gelegentlich lebende Exemplare in der Ostsee gefunden werden. 
Danksagung. Mein Dank gilt der Biologischen Anstalt Helgoland für die Überlassung eines Arbeitsplatzes an der Litoralstation in List. Herm Dr. Reise danke ich in besonderem Maße für die Bereitschaft zu klärenden Gesprächen und seine. Hilfe bei der kritischen Durchsicht des Manuskripts, Frau Halliger für ihre Unterstützung in technischen Fragen.

\section{LITERATUR}

Abel, C. \& Subclew, H. J., 1960. Trockenresistenz von Balanus improvisus. - Naturwissenschaften 47, 117.

Barnes, H., 1953. Size variations in the cyprids of some common barnacles. - J. mar. biol. Ass. U. K. $32,297-304$.

Barnes, H., 1957. Process of restoration and synchronisation in marine ecology. The spring diatom increase and the "spawning" of the common barnacle Balanus balanoides (L.). - Annls biol., Copenh. 33, 67-85.

Barnes, H., 1958. Regarding the southern limits of Balanus balanoides (L.). - Oikos 9, 139-157.

Barnes, H., 1963. Light, temperature and breeding of Balanus balanoides. - J. mar. biol. Ass. U. K. 43, 717-727.

Barnes, H., 1971. A review of some factors affecting settlement and adhesion in the cyprids of some common barnacles. In: Adhesion in biological systems. Ed. by R. S. Manly. Acad. Press, New York, 89-111.

Barnes, H. \& Powell, H. T., 1950. The development, general morphology and subsequent elimination of barnacle populations, Balanus crenatus and $B$. balanoides, after a heavy initial settlement. $-J$. Anim. Ecol. 19, 175-179.

Barnes, H. \& Powell, H. T., 1954. Onchidoris fusca Müller, a predator of barnacles. - J. Anim. Ecol. $23,361-363$.

Barnes, H. \& Crisp, D. J., 1956. Evidence of self-fertilization in certain species of barnacles. - J. mar. biol. Ass. U. K. 35, 631-639.

Barnes, H. \& Costlow, J. D., 1961. Larval stage of Balanus balanus (L.) da Costa. - J. mar. biol. Ass. U. K. $41,59-68$.

Barnes, H. \& Healy, M. J. R., 1965. Biometrical studies on some common cirripedes. I. Balanus balanoides: Measurements of the scuta and terga of animals from a wide geographical range. - J. mar. biol. Ass. U. K. 45, 779-789.

Barnes, H. \& Stone, R. L., 1973. The general biology of Verruca stroemia (O. F. Müller). II. Reproductive cycle, population structure, and factors affecting release of nauplii. - J. exp. mar. Biol. Ecol. 12, 279-297.

Barnes, H. \& Barnes, M., 1974. The responses during development of the embryos of some common cirripedes to wide changes in salinity. - J. exp. mar. Biol. Ecol. 15, 197-202.

Barnes, H. \& Klepal, W., 1974. The general biology of Verruca stroemia (O. F. Müller). IV. Effect of salinity and temperature on survival, behaviour and osmotic relations. - J. exp. mar. Biol. Ecol. $14,37-46$.

Barnes, H. \& Barnes, M., 1975. The general biology of Verruca stroemia (O. F. Müller). V. Effect of feeding, temperature, and light regime on breeding and moulting cycles. - J. exp. mar. Biol. Ecol. $19,228-232$.

Barnes, H., Finlayson, D. M. \& Piatigorsky, J., 1963. The effect of desiccation and anaerobic conditions on the behaviour, survival and general metabolism of three common cirripedes. $-\mathrm{J}$. Anim. Ecol. 32, 233-252.

Barnes, H., Reed, R. \& Topinka, J. A., 1970. The behaviour on impaction by solids of some common cirripedes and relation to their normal habitat. - J. exp. mar. Biol. Ecol. 5, 70-87.

Barnes, H., Barnes, M. \& Klepal, W., 1972. Some cirripedes of the French Atlantic coast. - J. mar. biol. Ass. U. K. 41, 187-194.

Barnett, B. E. \& Crisp, D. J., 1979. Laboratory studies of gregarious settlement in Balanus balanoides and Elminius modestus in relation to competition between these species. - J. mar. biol. Ass. U. K. 59, 581-590.

Barnett, B. E., Edwards, S. C. \& Crisp, D. J., 1979. A field study of settlement behaviour in Balanus balanoides and Elminius modestus (Cirripedia: Crustacea) in relation to competition between them. - J. mar. biol. Ass, U. K. 59, 575-580. 
Bassindale, R., 1936. The developmental stages of three English barnacles, Balanus balanoides (Linn.), Chthamalus stellatus (Poli), and Verruca stroemia (O. F. Müller). - Proc. zool Soc. Lond. $1936,57-74$.

Bassindale, R., 1964. British barnacles, with keys and notes for identification of the species. Acad. Press, London, 88 pp. (Synopses of the British Fauna, 14).

Bocquet-Védrine, J., 1963. Structure du test calcaire chez Chthamalus stellatus (Poli). - C. r. hebd. Séanc. Acad. Sci., Paris 257, 1350-1352.

Boëtius, J., 1952. Some notes on the relation to the substratum of Lepas anatifera L. and Lepas fascicularis E. et S. - Oikos 4, 312-317.

Bourget, E., 1977. Shell structure in sessile barnacles, - Naturaliste can. 104, 281-323.

Broch, H., 1924. Cirripedia thoracica von Norwegen und dem norwegischen Nordmeer. Eine systematische und biologisch-tiergeographische Studie. - Vidensk. Skr., Kristiania (Mat.-nat. KI.) $17,1-121$.

Buchholz, H., 1951. Die Larvenformen von Balanus improvisus. - Kieler Meeresforsch. 8, 49-57.

Campbell, A. C., 1977. Der Kosmos-Strandführer. Kosmos, Stuttgart, 320 pp.

Carli, A., 1966. Osservazioni sui Cirripedi della costa ligure Chthamalus stellatus (Poli) e Chthamalus depressus (Poli). - Boll. Musei Ist. biol. Univ. Genova 34, 117-137.

Connell, J., 1961a. Effects of competition, predation by Thais lapillus, and other factors on natural populations of the barnacle Balanus balanoides. - Ecol. Monogr. 31, 61-104.

Connell, J., 1961b. The influence of interspecific competition and other factors on the distribution of the barnacle Chthamalus stellatus. - Ecology 42, 710-723.

Connell, J., 1975. Some mechanisms producing structure in natural communities: a model and evidence from field experiments. In: Ecology and evolution of communities. Ed. by M. L. Cody \& J. M. Diamond. Belknap Press, Cambridge, Mass, 460-490.

Costlow, J. D., 1956. Shell development in Balanus improvisus Darwin. - J. Morphol. 99, $349-415$.

Crisp, D. J., 1950. Breeding and distribution of Chthamalus stellatus. - Nature, Lond. 166, 311-312.

Crisp, D. J., 1955. The behaviour of barnacle cyprids in relation to water movement over a surface. J. exp. Biol. 32, 569-590.

Crisp, D. J., 1957. Effect of low temperature on the breeding of marine animals. - Nature, Lond. 179, $1138-1139$.

Crisp, D. J., 1958. The spread of Elminius modestus Darwin in north-west Europe. - J. mar. biol. Ass. U.K. 37, 483-520.

Crisp, D. J., 1962. Planktonic stages of the Cirripedia Balanus balanoides (L) and Balanus balanus (L) from north temperate waters. - Crustaceana 3, 207-221.

Crisp, D. J., 1964. Surface chemistry, a factor in the settlement of marine invertebrate larvae. - Bot. Gothoburg. 3, 51-65.

Crisp, D. J., 1974. Factors influencing the settlement of marine invertebrate larvae. In: Chemoreception in marine organisms. Ed. by P. T. Grant \& A. M. Mackie. Acad. Press, London, 177-265.

Crisp, D. J. \& Barnes, H., 1954. The orientation and distribution of barnacles at settlement, with particular reference to surface contour. - J. Anim. Ecol. 23, 142-162.

Crisp, D. J. \& Bourget, E., 1985. Growth in barnacles. - Adv. mar. Biol. 22, 1-200.

Crisp, D. J. \& Davies, P. A., 1955. Observations in vivo on the breeding of Elminius modestus grown on glass slides. - J. mar. biol. Ass. U.K. 34, 357-380.

Crisp., D. J. \& Meadows, P. S., 1962. The chemical basis of gregariousness in cirripedes. - Proc. R. Soc. (B) $156,500-520$.

Crisp, D. J. \& Meadows, P. S., 1963. Absorbed layers: the stimulus to settlement in barnacles. - Proc. R. Soc. (B) $158,364-384$.

Crisp, D. J. \& Ritz, D. A., 1967. Changes in temperature tolerance of Balanus balanoides during its life cycle. - Helgoländer wiss. Meeresunters. 15, 98-111.

Crisp, D. J. \& Patel, B., 1969. Environmental control of the breeding of three boreo-arctic cirripedes. Mar. Biol. 2, 283-295.

Crisp, D. J., Southward, A. J. \& Southward, E. C., 1981. The distribution of the intertidal barnacles Chthamalus stellatus, Chthamalus montagui and Euraphia depressa. - J. mar. biol. Ass. U.K. 61, $359-380$.

Daniel, A., 1957. Mlumination and its effect on the settlement of barnacle cyprids. - Proc. zool. Soc. Lond. 129, 305-313. 
Daniel, A., 1958. The development and metamorphosis of three species of sessile barnacles. - J. Madras Univ. 28, 23-47.

Darwin, C., 1851. A monograph on the subclass Cirripedia, with figures of all species. Ray Soc., London, $400 \mathrm{pp}$.

Darwin, C., 1854. A monograph on the subclass Cirripedia, with figures of all species. Ray Soc., London, $684 \mathrm{pp}$.

Davenport, J., 1976. A comparative study of the behaviour of some barnacles exposed to fluctuating sea water concentrations. - J. mar. biol. Ass. U.K. 56, 889-907.

Emson, R. H., 1977. The feeding and consequent role of Eulalia viridis (Polychaeta) in intertidal communities. - J. mar. biol. Ass. U.K. 57, 93-96.

Fales, D. E., 1928. The light-receptive organs of certain barnacles. - Biol. Bull. mar. biol. Lab., Woods Hole 54, 534-547.

Fischer-Piette, E. \& Prenant, M., 1956. Distribution des cirripèdes intercotidaux d'Espagne septentrionale. - Bull. Cent. Étud. Rech. scient., Biarritz 1, 7-19.

Foster, B. A., 1967. A guide to the littoral balanomorph barnacles of New Zealand. - Tuatara 15, 75-86.

Foster, B. A., 1969. Tolerance of high temperatures by some intertidal barnacles. - Mar. Biol. 4, 326-332.

Foster, B. A., 1970. Responses and acclimitation to salinity in the adults of some balanomorph barnacles. - Phil. Trans. R. Soc. (B) 256, 377-400.

Foster, B. A., 1971. On the determinants of the upper limit of intertidal distribution of barnacles (Crustacea, Cirripedia). - J. Anim. Ecol. 45, 33-48.

Grainger, F. \& Newell, G. E., 1965. Aerial respiration in Balanus balanoides. - J. mar. biol. Ass. U.K. $45,469-479$.

Gutmann, W. F., 1960. Funktionelle Morphologie von Balanus balanoides. - Abh. senckenberg, naturf. Ges. 500, 1-43.

Gutmann, W. F., 1961. Die Siedlungsweise der Seepocke Balanus balanus. - Natur Volk 91, 171-181.

Gutmann, W. F., 1962. Beobachtungen zum Formproblem der Seepockenschale. - Natur Mus. Frankf., 92, 193-200.

Hancock, D. A., 1955. The feeding behaviour of starfish on Essex oyster bed. - J. mar. biol. Ass. U.K. 34, 313-331.

Hancock, D. A., 1957. The feeding behaviour of the sea urchin Psammechinus miliaris (Gmelin) in the laboratory. - Proc. zool. Soc. Lond. 129, 255-262.

Herz, L. E., 1933. The morphology of the later stages of Balanus crenatus Bruguiere. - Biol. Bull. mar. biol. Lab., Woods Hole $64,432-442$.

Hoek, P. P. C., 1909. Die Cirripedien des nordischen Planktons, VIII. - Nord. Plank. 11, 265-331.

Houghton, D. R. \& Stubbings, H. G., 1963. On the vertical distribution of Elminius modestus. - J. Anim. Ecol. 32, 193-201.

Jones, L. W. G. \& Crisp, D. J., 1954. The larval stages of the barnacle Balanus improvisus Darwin. Proc. zool. Soc. Lond. 123, 765-780.

Kaestner, A.; 1967. Lehrbuch der speziellen Zoologie. Fischer, Stuttgart, 1, (2) 849-1242.

Klepal, W., 1971. Chthamalus stellatus (Poli) und Chthamalus depressus (Poli) in der Adria. - J. exp. mar. Biol. Ecol. 7, 271-294.

Klepal, W. \& Barnes, H., 1975. Further observations on the ecology of Chthamalus depressus (Poli). J. exp. mar. Biol. Ecol. 17, 269-296.

Knight-Jones, E. W., 1953. Laboratory experiments on gregariousness during setting in Balanus balanoides and other barnacles. - J. exp. Biol. 30, 583 -598.

Knight-Jones, E. W. \& Waugh, G., 1949. On the larval development of Elminius modestus Darwin. J. mar. biol. Ass. U.K. 28, 413-428.

Knight-Jones, E. W. \& Moyse, J., 1961. Intraspecific competition in sedentary marine animals. Symp. Soc. exp. Biol. 15, 72-95.

Kalosváry, G. von, 1939. Über die Variablität der Cirripedien-Unterart Chthamalus stellatus stellatus (Poli). - Zool. Anz. 127, 159-169.

Kolosváry, G. von, 1941. Die Formenkreise der Chthamaliden. - Zool, Anz. 133, 67-81.

Krüger, P., 1927. Cirripedia. - Tierw. Nord- u. Ostsee 10d, 1-40. 
Krüger, P., 1940. Cirripedia. - Bronn's Kl. Ordn. Tierreichs 5 (Abt. 1, 3), 1-560.

Kühl, H., 1950. Uber die normale und die durch Gifte beeinflußte Metamorphose von Balanus improvisus Darwin. - Verh. dt. zool. Ges. 1949, 158-167.

Kühl, H., 1951. Vergleichende biologische Untersuchungen über den Hafenbewuchs. - Verh. dt. zool. Ges. 1950, 233-244.

Kühl, H., 1953. Uber das Aufsuchen des Siedlungsplatzes durch die Cyprislarven von Belanus improvisus Darwin. - Verh. dt. zool. Ges. 1952, 189-200.

Kühl, H. 1954. Über das Auftreten von Elminius modestus Darwin in der Elbmündung. - Helgoländer wiss. Meeresunters. 5, 53-56.

Kühl, H., 1963. Die Verbreitung von Elminius modestus Darwin (Cirripedia Thoracica) an der deutschen Küste. - Crustaceana 5, 99-111.

Kühl, H., 1967. Observations on the ecology of barnacles in the Elbe estuary. - Proc. Symp. Crustacea, mar. biol. Ass. India. 3, 965-975.

Kühl, H., 1968. Schiffsbewuchs und Hafenbewuchs. Deutsche Häfen 2 (Wilhelmshaven, Bremerhaven). - Schiff Hafen 20, (8), 3-6.

Larman, V. N. \& Gabbott, P. A., 1975. Settlement of cyprid larvae of Balanus balanoides and Elminius modestus induced by extracts of adult barnacles and other marine animals. - J. mar. biol. Ass. U.K. 55, 183-190.

Le Reste, L., 1965. Contribution à l'étude des larves de cirripèdes dans le golfe de Marseille. - Rec. Trav. Stn mar. Endoume 38, (54), 33-121.

Lewis, J. R., 1964. The ecology of rocky shores. Engl. Univ. Press, London, 323 pp.

Lochhead, J. H., 1936. On the feeding mechanism of the nauplius of Balanus perforatus Bruguière.J. Linn. Soc. (Zool.) 39, 429-442.

Luther, G., 1976. Bewuchsuntersuchungen auf Natursteinsubstraten im Gezeitenbereich des Nordsylter Wattenmeeres. - Helgoländer wiss. Meeresunters. 28, 145-166.

Meadows, P. S., 1969. Settlement, growth and competition in sublittoral populations of barnacles. Hydrobiologia 33, 65-92.

Moore, H., 1935. The biology of Balanus balanoides. IV. Relation to environmental factors. - J. mar. biol. Ass. U. K. 20, 279-307.

Moore, H. \& Kitching, F. A., 1939. The biology of Chthamalus stellatus (Poli). - J. mar. biol. Ass. U. K. 23, 521-541.

Moyse, J., 1963. A comparison of the value of various flagellates and diatoms as food for barnacle larvae. - J. Cons. perm. int. Explor. Mer 28, 175-187.

Moyse, J. \& Hui, E., 1981. Avoidance by Balanus balanoides cyprids of settlement on conspecific adults. - J. mar. biol. Ass. U. K. 61, 449-460.

Moyse, J. \& Knight-Jones, E. W., 1967. Biology of cirripede larvae. - Proc. Symp. Crustacea, mar. biol. Ass. India 2, 595-611.

Newell, R. C., 1970. Biology of intertidal animals. Logos Press, London, 555 pp.

Newman, W. \& Ross, A., 1976. Revision of the barnacles, including a catalogue of the species. Mem. S. Diego Soc. nat. Hist. 9, 1-108.

Paine, R. T., 1974. Intertidal community structure. Experimental studies on the relationship between a dominant competitor and its principal predator. - Oecologia 15, 93-120.

Parke, M. W. \& Moore, H., 1935. The biology of Balanus balanoides. II. Algal infection on the shell. J. mar. biol. Ass. U. K. 20, 49-63.

Patel, B., 1959. The influence of temperature on the reproduction and moulting of Lepas anatifera $\mathrm{L}$. under laboratory conditions. - J. mar. biol. Ass. U. K. 38, 589-597.

Powell, H. T., 1954. Occurrence of Chthamalus stellatus (Poli) in Fair Isle and Shetland. - Nature, Lond. 173, 119-120.

Pyefinch, K. A., 1948a. Methods of identification of the larvae of Balanus balanoides (L.), Balanus crenatus Brug. and Verruca stroemia (O. F. Müller). - J. mar. biol. Ass. U. K. 27, $451-463$.

Pyefinch, K. A., 1948b. Notes on the biology of cirripedes. - J. mar. biol. Ass. U. K. 27, 464-503.

Pyefinch, K. A., 1948c. The larval stages of Balanus crenatus Brug. - Proc. zool. Soc. Lond. 118, 916-923.

Rainbow, P. S., 1984. An introduction to the biology of British littoral barnacles. - Fld. Stud. 6, 1-51.

Relini, G., 1969. La distribuzione dei cirripedi toracici nei mari Italiana. - Arch. bot. biogeogr. ital. 4, 168-186. 
Remane, A., 1962. Cirripedia, Rankenfüßer. In: Handbuch der Biologie. Hrsg. von L. von Bertalanffy. Akad. Verl. Ges. Athenaion, Konstanz 6 (1), 271-272.

Ritz, D. A. \& Crisp, D. J., 1970. Seasonal changes in feeding rate in Balanus balanoides. - J. mar. biol. Ass. U. K. 50, 223-240.

Runnström, S., 1925. Zur Biologie und Entwicklung von Balanus balanoides (Linné). - Bergens Mus. Årb. (Naturv. R.) $5,1-46$.

Runnström, S., 1927. Uber die Plattenentwicklung von Verruca stroemia. - Bergens Mus. Ärb. (Naturv, R.) 3, 1-10.

Schäfer, W., 1938. Die geologische Bedeutung von Bohr-Organismen in tierischen Hartteilen, aufgezeigt an Balaniden-Schill der Innenjade. - Senckenbergiana 20, 304-312.

Schäfer, W., 1952. Biologische Bedeutung der Ortswahl bei Balaniden-Larven. - Senckenbergiana $33,235-246$.

Schütz, L., 1969. Okologische und biologische Untersuchungen an den Balaniden der Kieler Bucht (Crustacea, Cirripedia). - Faun.-ökol. Mitt. 3, 269-277.

Smith, F. G. W., 1946. Effect of water currents upon attachment and growth of barnacles. - Biol. Bull. mar. biol. Lab., Woods Hole 90, 51-70.

Smith, F. G. W., 1948. Surface illumination and barnacle attachment. - Biol. Bull. mar. biol. Lab., Woods Hole 94, 33-39.

Southward, A. J., 1955. On the behaviour of barnacles. I. The relation of cirral and other activities to temperature. - J. mar. biol. Ass. U.K. 34, 403-422.

Southward, A. J., 1957. On the behaviour of barnacles. III. Further observations on the influence of temperature and age on cirral activity. - J. mar. biol. Ass. U.K. 36, 323-334.

Southward, A. J., 1958. Note on the temperature tolerance of some intertidal animals in relation to environmental temperatures and geographical distribution. - J. mar. biol. Ass. U. K. 37, 49-66.

Southward, A. J., 1962. On the behaviour of barnacles. IV. The influence of temperature on cirral activity and survival of some warm-water species. - J. mar. biol. Ass. U.K. 42, 163-177.

Southward, A. J., 1964a. The relationship between temperature and rhythmic cirral activity in some cirripedes considered in connection with their geographical distribution. - Helgoländer wiss. Meeresunters. 10, 391-403.

Southward, A. J., 1964b. On the European species of Chthamalus stellatus (Cirripedia). - Crustaceana $6,241-254$.

Southward, A. J., 1967. Recent change in abundance of intertidal barnacles in south-west England: a possible effect of climatic deterioration. - J. mar. biol. Ass. U.K. 47, 81-95.

Southward, A. J., 1976. On the taxonomic status and distribution of Chthamalus stellatus (Cirripedia) in the north-east Atlantic region: with a key to the common intertidal barnacles of Britain. J. mar. biol. Ass. U.K. 56, 1007-1028.

Southward, A. J. \& Crisp, D. J., 1954. Recent change in the distribution of the intertidal barnacles Chthamalus stellatus Poli and Balanus balanoides L. in the British Isles. - J. Anim. Ecol. 23, $163-177$.

Southward, A. J. \& Crisp, D. J., 1956. Fluctuations in the distribution and abundance of intertidal barnacles. - J. mar. biol. Ass. U.K. 35, 211-229.

Southward, A. J. \& Crisp, D. J., 1963. Barnacles of European waters. In: Catalogue of main marine fouling organisms. Organisation for Economic Cooperation and Development, Paris, 1, 1-46.

Southward, A. J. \& Crisp, D. J., 1965. Activity rhythms of barnacles in relation to respiration and feeding. - J. mar. biol. Ass. U.K. 45, 161-185.

Stone, R. L. \& Barnes, H., 1973. The general biology of Verruca stroemia (O. F. Müller). I. Geographical and regional distribution: cirral activity and feeding. - J. exp. mar. Biol. Ecol. 12, $167-185$.

Subklew, H. J., 1969. Zur Okologie von Balanus improvisus. - Limnologica 7, 1-147.

Thörner, E. \& Ankel, W. E., 1966. Die Entenmuschel Lepas fascicularis in der Nordsee. - Natur Mus. Frankf. 96, 209-220.

Thompson, J. V., 1830. Zoological researches and illustrations: on the Cirripedes or barnacles. King \& Ridings, Cork, 1 (4), 69-88.

Visscher, J. P., 1928. Reaction of the cyprid larvae of barnacles at time of attachment. - Biol. Bull. mar. biol. Lab., Woods Hole 54, 327-335. 
Visscher, J. P. \& Luce, R. H., 1928. Reactions of the cyprid larvae of barnacles to light with special reference to spectral colours. - Biol. Bull. mar. biol. Lab., Woods Hole 54, 336-350.

Walker, G., 1971. A study of the cement apparatus of the cypris larva of the barnacle Balanus balanoides. - Mar. Biol. 9, 205-212.

Walley, L. J., 1965. The development and function of the oviducal gland in Balanus balanoides. - J. mar. biol. Ass. U.K. 45, 115-128.

Weiss, C. M., 1947. The effect of illumination and stage of tide on the attachment of barnacle cyprids. - Biol. Bull. mar. biol. Lab., Woods Hole 93, 240-249.

Weltner, W., 1892. Nachträge zur Fauna von Helgoland III, zur Cirripedienfauna von Helgoland. Zool. Jb. (Syst. Okol. Geogr. Tiere) 6, 453-455.

Wolf, P. de, 1973. Ecological observations on the mechanisms of dispersal of barnacle larvae during planktonic life and settling. - Neth. J. Sea Res. 6, 1-129.

Yule, A. B. \& Walker, G., 1984. The adhesion of the barnacle Balanus balanoides to slate surfaces. J. mar. biol. Ass. U.K. 64, 147-156. 